\title{
Technical Assessment of Critical Plasma-Materials Interaction (PMI) and High Heat Flux (HHF) Issues for Alternative Fusion Concepts (AFCs)
}

James N. Downing

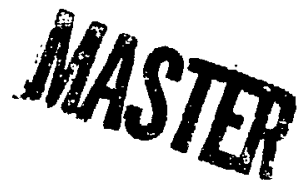

\section{DISCLAIMER}

\begin{abstract}
This repmit was prepared as an account of work sponsored by an agency of the United States Guvernment. Neither the United States Governmen: nor any agency thereof, nor any of their empliares. nakes any warranty. express ar implied or assumes any legal iability or responsibilit; for the aciuracy, cumpleteness, or usefulness of any information, apparatus, product. or process disclosed, wrepresents that its use would not infringe privately owned rights. Reference herein to any sperific cornmercial product, process, or service hy iracle name, trademark. manufacturer, ur otherwise dres not necessarily constitute or imply its endorsement, recommendation, or favoring by the United States Governnient or any agency thereof The views and apinions of authors expressed herein do not recessarily state or reflect those of the United States Government or any agency thereof.
\end{abstract}


This document was prepared in support of sections in the Magnetic Fusion Energy Plasma Interactive and High Heat Flux Components, Volume I Technical Assessment of the Critical Issues and Problem Areas in the Plasma Materials Interaction Field (UCLA/PPG-765, Vol. 1, January 1984), and Volume II Technical Assessment of the CriticaI Issues and Problem Areas in High Heat Flux Materiais and Component Development (PPG-815, UCLA-ENG-84-25, June 1984). 

1. $\mathrm{AFC}(\mathrm{AFCs})$
Alternative Fusion Concept(s)
2. ARE
Aspect-Ratio-Enhancement
3. $\operatorname{CCTX}$
Collisionless Compact Toroid Experiment
4. CRFPR
Compact RFP Reacter
5. CT (CTs)
Compact Toroid(s)
6. CIOR
Compact-Toroid Fusion Reactor
7. DEMO
Demostration Feartor
8. EBT
Elmo Bumpy Torus
9. EBTR
EB'T Reactor
10. ECRH
Electron Cyclotron Resonance Heating
11. ETR
Engineering Test Reactor
12. eXo-FPC
External to FPC
13. FPC
14. FRC (FR̈Cs)
Fusion Power Core
15. $\mathrm{FW} / \mathrm{B} / \mathrm{S}$ (FWBS)
F:eld-Reversed Configuration(s)
16. FY
First Wall.'Blanket/Shield
17. HHF
Fiscal Year
18. HFD
Hish Heat Flux
19. ICRH
Hig. Power Density
20. ICRF
Ion Cyclotron Resonance Heating
21. $\mathrm{LH}$
Ion Cyclotron Resonance Frequency
22. LPD
Lower Hybrid
23. $M F E$
Low Power Density
Magisetic Fusion Energy
24. MSR
Modular Stellarator Reactor
25. MWt
Megawatt Thermal
26. NBI
Neuiral Beam Injector
27. NBT
Nagoya Bumpy Torus
28. $\mathrm{OH}$
Ohmic Heating
29. OHTE
ohmically Heated Toroidal Experiment
30. ORNL
Oak Ridge National Laboratory 
31. PMI

32. $R F$

33. RFP

34. RFPR

35. SOL

36. Starfire

37. $\mathrm{S} / \mathrm{T} / \mathrm{H}$

38. TF
Plasma-Material Interaction

Radio Frequency

Reversed-Field Pinch

Reversed-Field Pinch Reactor

Scrape-off Layer

A Tokamak Reactor Reference Point Design

Stellarator/Torsatron/Heliotron

Toroidal Field 
TECHNICAL ASSESSMENT OF CRITICAL FLASMA-MATERIALS INTERACTION (PMI) AND HIGF HEAT FLUX (HHF) ISSUES FOR ALTERNATIVE FUSION CONCEPTS (AFCS)

by

James N. Downing

\section{ABSTRACT}

A number of approaches to fusion energy are being pursued as alternative fusion concepts (AFCs). The goal of these systems is to provide a more desirable method of producing fusion energy than the mainline programs. Some of the AFCs have both a Low Power Density (LPD) option and a High Power Density (HPD) option. A summary of representative AFC prograns and their associated PMI and HHF issues is followed by the technical assessment of the crisical issues. These requirements are discussed relative to the mainline and/or HPD components. The HPD options are contrasted with a tabulation of the characteristics of components for the Reversed-Field Pinch (RFP), which is representative of the HPD concept.

\section{INTRODUCTION TO ALTERNATIVE FUSION CONCEPTS}

The development of magnetic fusion energy (MFE) is being pursued via two mainline programs, the tokamak and the tandem mirror. At a considerably lower level of effort, a number of less developed approaches are being pursued as alternative fusion concepts (AFCs). These approaches may eventually lead to a simpler, less expensive, or more desirable method of producing fusion energy. Although there are many concepts which belung to the AFC categcry, a realistic grouping of the most prominent concepts is as follows:

- ELMO or Nagoya Bumpy Torus (EBT/NBT)

- Stellarator/Torsatron/Heliotron (S/T/H)

- Reversed Field Pinches (RFP), OHTE, High Field Tokamak 
- Compact Toroids (CTs) [Field-Reversed Configurations (FRCs) and Spheromaks ]

Some of the above concepts have both a "conventional" or low power density (LPD) design point and a "compact" or high power density (HPD) design point. These "compact" systems are characterized by a fusion power core (FPC) of reduced size/mass with system power densities approaching that of a light water fission reactor $\left(\sim 19.8 \mathrm{MWt} / \mathrm{m}^{3}\right)$. Toroidal confinement systems that could contribute to the "compact" reactor option are as follows:

- Compact RFP Reactor (CRFPR)

- OHTE Reactor

- High-Field Tokamak Reactor (Riggatron, HFCTR)

- Heliacs (Compact S/T/H)

- Compact toroids (FRCs or spheromaks)

The "conventional" power density AFC systems have system power densities of $\leq 0.50\left(\mathrm{MWt} / \mathrm{m}^{3}\right)^{\perp}$ which are comparable to the tokamak reference point reactor design, Starfire $\left(0.30 \mathrm{MWt} / \mathrm{m}^{3}\right)^{1}$, and utilize superconducting coils. The HPD toroidal fusion options are classified as plasma toroids using resistive coils to provide high density confinement. These devices are true alternate concepts because they represent an end product that is significantly different from the mainline approaches. Three systems that have been studied as power reactors are the Riggatron, ${ }^{-7}$ the OHTE ${ }^{-9}$ and the CRFPR.10-13, * These devices rely on ohmic heating $(\mathrm{OH})$ to achieve ignition, with the high field tokamak, to varying degrees, also requiring compressional or RF heating. The fusion power core (FPC) for these systems has a smaller volume, mass, and cost than the conventional approaches. This reduced size/mass FPC allows the potential for "block" installation and maintenance. The development of some of these HPD systems requires only the extension of existing technologies instead of the development of new technologies such as superconducting coils and auxiliary heating techniques; therefore, they have the potential for a rapid, minimum-cost development.

\footnotetext{
${ }^{\star}$ Information provided by R.A. Krakowski, Los Alamos National Laboratory Group CTR-12.
} 
II. SUMMARY OF ENGINEERING AND TECHNOLOGY RESEARCH AND DEVELOPMENT NEEDS FOR AFCS RELATED TO PMI

An assessment of the future engineering development needs of alternative fusion concepts (AFC) has been presented to the Future Engineering Development Needs for Magnetic Fusion Workshop (August 3-4, 1982) 1 The engineering problems of the AFCs were contrasted with similar problems which have been assessed for the conventional tokamak approach to fusion energy.

\section{A. Conventional AFCs}

With the possible exception of the less developed CT concepts, the future engineering requirements for the LPD AFCs appeared to be similar (or somewhat more demanding as in the case of $S / T / H$ ) to the requirements of the mainline tokamak program. The "long-pulsed conventional RFP may present an equivalent, if not somewhat easier and more rapid, engineering path to fusion power than an equivalently long pulsed tokamak, if both systems operate with nominally the same plasma transport at fusion conditions."1

The future engineering needs of both the mainline and conventional AFC approaches are summarized below: ${ }^{1}$

- Plasma engineering (auxiliary and'or startup heating, impurity/ash/fuel control, current drive versus long-pulsed operation).

- First-wall/liniter systems (transient thermal effects, sputtering, radiation effects, tritium permeation/retention/recycle, end-of-life mechanism(s) and lifetime, maximum operating temperature and overall plant efficiency).

- Blanket/shield (materials compatibility, radiation damage, solidbreeder properties versus liquid-metal breeder containment).

- Magnets (thermomechanical/electromechanical properties, radiation effects io conductors and insulators, reliability, maximum fields and hybrid magnets, size/modularity).

- Remote maintenance (better definition of maintenance scheme and downtime, need for less massive modules, quantify relative merits of block versus patch maintenance FPC reliability analysis). 


\section{B. HPD Systems ${ }^{1-3}, 8^{-12}, 14,15$}

In many areas HPD systems require the same or similar ent;ineering developments as the conventional approaches; however, the following changes in system parameters are directly related to HPD operation: ${ }^{1}$

- Increased plasma power density $\left(72 \mathrm{MWt} / \mathrm{m}^{3}, 82.4 \mathrm{MWt} / \mathrm{m}^{3}\right.$, and $460 \mathrm{MWt} / \mathrm{m}^{3}$ for the CRFPR, OHTE, and Riggatron respectively).

- Increased first-wall neutron current $\left(19.5 \mathrm{MW} / \mathrm{m}^{2}\right.$ for CRFPR and OHTE, and $68.0 \mathrm{MW} / \mathrm{m}^{2}$ for the Riggatron).

- Increased surface heat flux (4-5 $\mathrm{MWt} / \mathrm{m}^{2}$ for CRFPR and OHTE and 20-50 $\mathrm{MWt} / \mathrm{m}^{2}$ for the Riggatron).

- Increased peak $\left(\gtrsim 100 \mathrm{MWt} / \mathrm{m}^{3}\right)$ and average $\left(-50 \mathrm{MWt} / \mathrm{m}^{3}\right)$ power density within a tritium breeding blanket.

- Increased radiation and heat fluxes at the resistive magnet coils in systems designed to operate only with a thin HPD blanket placed between the coil and the plasma.

A summary of compact reactor technology requirements is given in Table I.17 These changes do not, however, lead to more severe problems for HPD systems. The ratio of particle flux to neutron current incident on a FW should be similar for both the compact and the mainline approaches. The HPD systems just achieve both their neutron and erosion lifetime "fluences" in a chronologically shorter lifetime. For example, a tokamak will utilize a certain limiter area at certain power flux $\left(\sim 5 \mathrm{MW} / \mathrm{m}^{2}\right)$ for a certain fusion power output. The HPD systems will utilize the same area at the same power flux. The difference is the ratio of the limiter area to total area.

III. SUMMARY OF AFC PROGRAMS AND ASSOCIATED PMI AND HHF ISSUES

A. Compact Toroid $4,18-24$

1. Introduction. Compact Toroids (CT) are axisymmetric plasma configurations whose center is not linked by magnet coils, vacuum walls, etc. This feature simplifies the geometry for reactor components and offers the potential for "compact" systems. The CT can be moved from one region to another. Some of the CT reactor concepts invalve schemes which separate the source of the plasma from the reactor burn region. This process avoids highneutron and thermal fluxes in the plasma formation region and allows 
considerable freedom of choice in the method used to produce the plasmoid and in the initial plasma conditions.

A number of plasma configurations are possible within the CT concept; however, the spheromak and the field reversed configuration (FRC) are the main focus of the current research. The spheromak has two components (poloidal and toroidal) of magnetic field which are comparable in magnitude and form nested flux surfaces similar to the RFP. The plasma is confined in a near-minimum energy state (Taylor state) where both moderate beta $(\sim 0.1)$ and low beta equilibria are possible. The FRC utilizes only a poloidal magnetic field and is inherently a high beta $(0.8)$ configuration. Stability conditions require an oblate shape for the spheromak and a prolate shape for the ${ }^{\prime} R C$. The magnetic field structure of these configurations provides a natural magnetic divertor.

The near term ('83-'84) CT program² is to select the best methods for forming and stabilizing spheromaks and FRCs. Existing devices will be used to study the formation of "moderately hot (100-200 eV), grossly MHD stable plasmas." 22 In the 1985-86 time frame a single reactor scenario for each concept (Spheromak and FRC) will be selected. These two concepts will be evaluated until a selection is made for the Collisionless Compact Toroid Experiment (CCTX) in the 1589-90 time frame. If subsequent experiments on the CCTX demonstrate major advantages over other alternative approaches to fusion then the focus of AFC development could be shifted towards an ignition device for the CT.

A list of some representative compact toroids is given in Table II. Device parameters are given, and the area(s) where each device will contribute to the CT program is indicated.

2. Magnetic Divertor. To utilize the natural divertor action of the spheromak or FRC configurations the separatrix must be maintained within the vacuum rezion. For the axially moving FRC the reduction in field diffusion resulting from the axial motion $\left(-5 \times 10^{7} \mathrm{~cm} / \mathrm{s}\right)$ satisfies this condition. Active feedback is necessary to maintain the appropriate boundary conditions for spheromak configurations. If the separatrix is allowed to move into the conducting wall, the divertor action is lost and the first wall will become the primary PMI zone. As long as the divertor action persists, the PMI and HHF issues will be the same as the mainline program where similar fusion power 


\section{Plasma Engineering Systems}

- Operate vith high toroidal current density $\left(>10 \mathrm{MA} / \mathrm{m}^{2}\right)$ in a dense plasma to achieve DT ignition by ohmic heating ãlone, possibly wirh auxiliary-heating boost or plasma preconditioning in order to minimize volt-second consumption vilile attaining ignition.

- Understand means to provide fueling, jmpurity/ash control, and steadystate current drive in dense plasma.

- Plasma edge control, dense gas blanket, isolation of plasma from Fy. ${ }^{2}$

- Examine potential of compact options for confinement systems that operate with currentless plasma.

\section{Nuclear Systems}

- High heat-flux (3-5 $\left.\mathrm{HW} / \mathrm{m}^{2}\right) \mathrm{FW}$ and high-power-density breeding blanket (100 $\mathrm{MHt} / \mathrm{m}^{3}$ peak, $50 \mathrm{MHt} / \mathrm{m}^{3}$ average) precludes use of primary candidate alloy stainless steel (PCASS) at the FW and solid trittum breeders within the blanket.

- Control/understand FW sputter erosion through use of magnetic divertor, dense gas blankets. and/or tailoring of plasma edge conditions.

- Interrelationship between FW temperature, FV life-limiting mechanisms, maximum blanket temperature, blanket thickness, and overall plant efficiency needs better resolution.

- Single/few-piece FW/B/S construction for purposes of "block" maintenance requires careful resolution, particularly with resuect to coolant and vacuum ducting.

- Better resolve tradeoff between reduced inner coil shield thickness and increased biological exo-FPC equipment radiation shielding.

- Better resolve interrelationships between overall systen stress, reliability, and availability.

\section{Magnet Systems}

- Very high-rield ( $30 \mathrm{~T}$ ) resistive $\mathrm{OH}$ coils required by ohmically heated compact tokamak reactor (Riggatron).

- Most compact systems require resistive coils to operate in high radiation field. Need exists to understand response of such coils (conductor and insulation) and life-limiting mechanisms (svelling, resistivity change, structural integrity, etc.).

- Certain compact options successfully trade off higher recirculating pover and $B O P^{C}$ cost for reduced shield and coll costs; this tradeoff requires additional study.

\section{Remote Maintenance}

- The basic maintenance approach differs considerably from the conventional mainline and AFC concepts; total "block" malntenance of the FW/B/S (200-400 tonne) is proposed. The merits of "block" versus "patch" maintenance require further examination.

- The topology of coolant and vacuum ducts, the size of which should not change for a given total pover output, and the PPC, which is decreased in volume by a factor of 10-30, must be resolved and reconciled with the "block" maintenance approach.

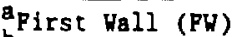

birst Yall/Blanket/Shield ( $\mathrm{FH} / \mathrm{B} / \mathrm{S})$

Balance of Plant (BOP)
} 
TABLE II

REPRESENTATIVE COMPACT TOROIDS

\begin{tabular}{|c|c|c|c|c|c|}
\hline Device & $\begin{array}{l}\text { Laboratory/ } \\
\text { Country }\end{array}$ & $\begin{array}{c}\text { Major } \\
\text { Radius } \\
\quad(\mathrm{II}) \\
\end{array}$ & $\begin{array}{c}\text { Minor } \\
\text { Radius } \\
\text { (m) } \\
\end{array}$ & $\begin{array}{l}\text { Toroidal } \\
\text { Plasma } \\
\text { Current } \\
\text { (MA) } \\
\end{array}$ & $\begin{array}{l}\text { Progran } \\
\text { Contribut } \\
\end{array}$ \\
\hline \multicolumn{6}{|l|}{ SPHEROMAKS } \\
\hline $\operatorname{cTX}$ & Los Alamos & 0.44 & 0.26 & 0.4 & $C, F, S, S T$ \\
\hline ES & Los Alamos & 0.25 & 0.15 & 0.2 & $\mathrm{ST} ; \mathrm{F}$ \\
\hline $\mathrm{C} \theta \mathrm{P}$ & U. of Wash. & 0.04 & 0.04 & 0.01 & $F, M$ \\
\hline MS & U. Maryland & 0.09 & 0.09 & 0.10 & $C, F$ \\
\hline Proto S-1C & PPPL & 0.12 & 0.08 & 0.06 & $C, F, S$ \\
\hline S-1 & PPPL & 0.50 & 0.27 & $0.2(0.4)$ & $C, F, S$ \\
\hline СТСC-1 & JAPAN & 0.26 & 0.14 & 0.2 & $C, F, M$ \\
\hline
\end{tabular}

$\underline{\text { FRCs }}$

$\begin{array}{llllll}\text { IRX-C } & \text { LOS Alamos } & 0.07 & 0.03 & 1.5 & \mathrm{C}, \mathrm{S}, \mathrm{T} \\ \text { CTTX-1 } & \text { PENN STATE } & 0.02 & 0.01 & 0.14 & \mathrm{H}, \mathrm{T} \\ \text { TRX-2 } & \text { MSNW } & 0.045 & 0.025 & 0.75 & \mathrm{C}, \mathrm{F} \\ \text { BN-1 } & \text { USSR } & 0.05 & 0.025 & 0.5 & \mathrm{~F}, \mathrm{~T} \\ \text { TOR } & \text { USSR } & 0.07 & 0.03 & 1.1 & \mathrm{~F}, \mathrm{~T} \\ \text { TL } & \text { USSR } & 0.04 & 0.02 & 0.3 & \mathrm{~F}, \mathrm{~T}, \mathrm{CH} \\ \text { NUCTE-2 } & \text { JAPAN } & 0.028 & 0.12 & 1.6 & \mathrm{C}, \mathrm{F} \\ \text { OCT } & \text { JAPAN } & 0.035 & 0.02 & 0.5 & \mathrm{~F}, \mathrm{~T} \\ \text { PIACE } & \text { JAPAN } & 0.026 & 0.01 & 0.6 & \mathrm{C}, \mathrm{S}, \mathrm{T} \\ \text { STP-L } & \text { JAPAN } & 0.01 & 0.01 & 1.2 & \mathrm{C}, \mathrm{S}\end{array}$

Program Corıtributions: confinement (C), compressional heating (CH), formation (F), merging (M), stability (S), sustainment (ST), Translation ( $T$ ). 
outputs produce heat flux problems similar to those which occur in the divertor chamber of a tokamak or the end cell of a mirror machine.

3. FRC Formation and Heating, FRCs have been formed using very fast (high voltage) low bias field theta pinches which utilize shock heating ro achieve high initial plasma temperatures. Modest amounts of adiabatic compression would then be sufficient to ignite the plasmoid. The components required to form the plasma in this manner are high voltage capacitor banks and vacuum vessels (first walls) which are composed of electrically insulating materials. This formation technique is considered undesirable and a main thrust in the program is to "develop reactor relevant formation techniques for obtaining configurations with high poloidal flux."22 The goal is to form FRC plasmas on 30-100 us formation timescales ('85-'87) and to form reactor plasmas using slow formation techniques with most of the magnetic energy supplied on longer than 5-ms timescales. The emphasis will shift from shock heating to ohmic heating (perhaps coupled with auxiliary heating) ('85-'87) and adiabatic compression to reach ignition conditions.

A preliminary layout for a Compact-Toroid Fusion Reactor (CTOR) based on the FRC 3 is shown in Fig. 1, and a schematic view of the burn chamber is shown in Fig. 2. The physical parameters for this burn chamber are listed in Table III.23 The magnetic fields are supplied by superconducting magnet coils and no active coils are present in the burn section. The blanket structure operates in a thermally steady state because of the large energy content of the blanket and the short time interval $(\sim 5 s)$ between the translating piasmoids.

A major concern is the thermal-fatigue lifetime of the first wall. Radiation flux due to the final compression stage produces severe wall loading and thermal cycling at the inlet to the burn section. A high-strength Cu alloy (AMAX - 0.06\% $\mathrm{Mg}, 0.15 \% \mathrm{Zr}, 0.4 \% \mathrm{Cr}$, balance $\mathrm{Cu}$ ) is suggested as the potential first wall material, at least for the first few meters of the burn chamber. This section of the first wall may have to be replaced periodically; however, the physical design of the reactor should allow this replacement with a minimal impact on the plant availability.

At the exit end of the reactor the magnetic field lines are flared, and the thermal conduction energy ( $900 \mathrm{MJ} /$ pulse) is collected in a $200 \mathrm{~m}^{2}$ cylindrical beam dump $8-\mathrm{m}$ long and $4-\mathrm{m}$ in radius, as is listed in Table III. 
Parameter

Length, $L(m)$

Blanket thickness, $\Delta b(m)$

Conducting shell

- Thickness (m)

- Fraction of conductor in shell

Shield thickness (m)

Superconducting coil

- Radius (m)

- Magnetic field strength (T)

First wall

- Flared radils, $r_{W}(m)$

- Material

- Thickness (mm)

- Maximum bulk temperature rise $(K)^{a}$

- Maximum thermal differential (K)

- Maximum thermal stress (MPa)

Beam dump (end of burn chamber)

- Cylindrical geometry [radius

- Surface area $\left(n^{2}\right)$

- Maximum thermal load $\left(\mathrm{MW} / \mathrm{m}^{2}\right)$

- Average thermal load $\left(\mathrm{MW} / \mathrm{m}^{2}\right)$

- Material

- Thickness (min)

- Maximum bulk temperature rise (K)

- Maximum thermal differential (K)

- Maximum thermal stress (K)
Value

40

0.48

0.05

0.7

1.5

$3.2-3.6$

$3.5-1.5$
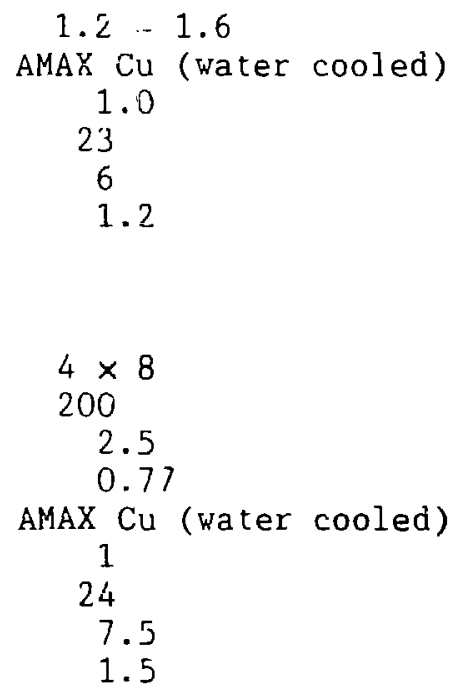

\footnotetext{
axcursion at most severe location (burn chamber inler).
} 
The heat load on tinis surface $\left(2.5 \mathrm{MW} / \mathrm{m}^{2}\right.$ peak) is then similar to that encountered by the first wall $\left(2.0 \mathrm{MW} / \mathrm{m}^{2}\right)$ and, using a similar construction, no thermal fatigue problems are expected.

4. Spheromak Formation and Heating. Stable spheromaks have been produced by (1) a combined induction and electrode discharge technique (PS-2 at the University of Maryland); (2) a coaxial gun (CTX at Los Alamos National Laboratory and BETA-II at Lawrence Livermore National Laboratory); and (3) an inductive, electrodeless discharge technique (S-1 at Princeton Plasma Physics Laboratory). Wiih one exception the plasma temperature has been limited by impurities to $<50 \mathrm{eV}$. A near term goal ('83-'85) of the spheromak program is to utilize impurity control techniques to improve the conditions within the plasma source(s) so that >100-eV plasmas can be produced. The CTX experiment has successfully met this goal by producing spheromak plasmas with electron temperatures of $\sim 150 \mathrm{eV}$. Auxiliary heating of the same type being developed for the mainline programs and/or adiabatic compression or ohmic heating can be utilized to raise the plasma temperature to $>0.5 \mathrm{keV}(' 85-' 87)$.

A particular scheme $(\mathrm{CTX})^{20}$ which has connected divertor surfaces offers the possioilicy of utilizing the continuous injection of magnetic helicity for ohmic heating and fueling of the fusion plasma. A schematic drawing of this steady state spheromak concept is shown in Fig. 3. The close coupling of the magnetic helicity injection electrodes (which are also the tarmination points of the connected divertor field lines) with the fusion plasma may impose more severe conditions on these surfaces with regard to erosion and sputtering than for conventional divertor compcnents; however, experiments with magnetoplasmadynamic arcs ${ }^{21}$ indicate that the level of impurities from the metal electrodes can remain small.

\section{B. Reversed Field Pinches (RFP)}

1. Introduction.25,26,27 The Reversed Field Pinch (RFP) is a high- $\beta$, a:isymmetric, toroidal magnetic confinement system that uses both toroidal $\left(B_{\phi}\right)$ and poloidal ( $\left.B_{\theta}\right)$ magnetic fields to confine hot plasma in a near-minimum energy state. RFP confinement relies strongly on the poloidal self-field generated by toroidal currents, and requires only modest external toroidal confinement fields. As in tokamaks, equilibrium may be provided by either externally applied vertical fields, a conducting toroidal shell, or some 
combination of both. The RFP may require a conducting shell to stabilize MHD modes with wavelengtiss longer than the shell radius, $r_{w}$. Stability at high beta (0.1-0.2) results from high nagnetic shear and a conducting shell. The pitch parameter, $q$, for the RFP is low on axis, -0.2 , and decreases with minor radius, passing through $q=0$ and becoming regative in the suter regions of the plasma. This results in two important features for the RFP. The first is that there is no constraint imposed on the aspect ratio: therefore, it can be chosen to optimize the engineering design. The second is that the toroidal current density can be high; therefore, the RFP offers the potential to achieve ignition by ohmic heating alone. Auxiliary heating components are not necessary. Since the poloidal field decreases with inczeased distance from the plasma, both the magnetic field at the coils and the current density in the coils for a given $B^{2}$ in the plasma are reduced compared to schemes utilizing the toroidal field for confinement. Superconducting coils can be replaced with normal conductors while maintaining a low recirculating power fraction.

RFP discharges last at least an order of magnitude longer than would be expected based on resistive diffusion. This "dynamo" action is currently understood in terms of the Taylor theory; the RFP maintains a near-minimum energy state by a continual self-relaxation process. The process of self-relaxation may allow the use of a low-frequency (few kHz) "F- $\theta$ pumping"25 technique to drive steady-state plasma currents

The larger devices (OHTE, 2T-40M, and HBTX-1A) have had difficulties at the higher current levels where the corresponding average thermal heat loads on the first walls are $\geq 1 \mathrm{MW} / \mathrm{m}^{2}$. Small areas of the vacuum liner in these devices have received 1 :al heat fluxes which were sufficient ro melt the liner (0.015-inch thick Inconel 625) locally and produce a loss of vacuum integrity.

The program plan for the development of the RFP corfinement system has two specific goals: "The advancrment of the data base for axisymmetric toroidal, high beta, confinement systems; and the assessment of the physics and technology required for compact high-energy-density fusion reactor systems."26 The critical issues that involve PMI and HEF issues are as follows: 
1. The development of the technology for high-power-density systems, such as high heat flux components for first wall limiters, and divertors, radiation-resistant materials, and high power density blankets.

2. The control of impurities and density.

3. The evaluation of the need for a conducting shell to provide equilibrium and stability.

A list of near-term RFP devices is given in Table IV. OHTE is included in this list because $j t$ can operate either as an RFP or an OHTE by changing the arrangement of the currents in the helical windings. The major role of these near-term devices is to expand the data base of RFP toroidal confinement physics. Within the design constraints of the devices, the effects of field errors and limiter/first wall systems on the confinement will be evaluated. ZT-40M will also study current drive utilizing the F- $\theta$ pumping scheme.

An overview of a program designed to take the RFP to commercial demonstration of fusion power is shown in Fig. 4, and a listing of key parameters is given in Table $V$. To adequately address the critical PMI and HHF issues for reactor-like conditions it will be required to extend the RFP physics and tecinnology data base. A higher current (0.6-2 MA), longer pulse ( $-250 \mathrm{~ms}$ ), high energy density machine (ZT-H) has been proposed. If approved

TABLE IV

REPRESENTATIVE RFPS

\begin{tabular}{|c|c|c|c|c|}
\hline Device & $\begin{array}{c}\text { Laboratory/ } \\
\text { Country } \\
\end{array}$ & $\begin{array}{r}\text { Major } \\
\text { Radius } \\
\text { (merers) } \\
\end{array}$ & $\begin{array}{r}\text { Minor } \\
\text { Radius } \\
\text { (meters) } \\
\end{array}$ & $\begin{array}{c}\text { Plasina } \\
\text { Current } \\
\text { (MA) } \\
\end{array}$ \\
\hline $\mathrm{OHTE}^{\mathrm{a}}$ & GAT & 1.24 & 0.19 & $0.25-0.50$ \\
\hline ZT- $40 M$ & Los Álamos & 1.14 & 0.20 & $0.06-0.24$ \\
\hline ETA BETA-2 & ITALY & 0.65 & 0.125 & $0.05-0.20$ \\
\hline HBTX 1-A & UK & 0.80 & 0.26 & $0.10-0.50$ \\
\hline REPUTE $^{b}$ & JAPAN & 0.80 & 0.20 & $(0.4)$ \\
\hline$S T P-3 M^{b}$ & JAPAN & 0.50 & 0.09 & $(0.3)$ \\
\hline
\end{tabular}

aprivately funded

bunder construction 1984 


\begin{tabular}{|c|c|c|c|c|c|c|c|c|c|}
\hline Parameter & Present & $\begin{array}{l}\text { High } \\
\text { Current }\end{array}$ & A & B & DD Mode & DT Mode & DD Mode & DT Mode & DD Mode \\
\hline$r_{w}(\mathbb{m})$ & 0.2 & 0.2 & 0.4 & 0.25 & 0.25 & 0.55 & 0.42 & 0.75 & 0.6 \\
\hline$R_{T}(m)$ & 1.14 & 1.14 & 2.4 & 24 & 2.4 & 3.2 & 3.2 & 4.3 & 4.3 \\
\hline$I_{\phi}(M A)$ & 0.2 & 0.6 & 2.0 & 2.0 & 4.0 & 10.0 & 12.5 & 18.5 & 25.0 \\
\hline $\mathrm{J}_{\phi}\left(\mathrm{MA} / \mathrm{m}^{2}\right)$ & $\therefore .6$ & 4.8 & 4 & 10 & 20 & 10.5 & 22.5 & 10.5 & 22.5 \\
\hline$E_{S T P R}(G J)$ & 0.0011 & 0.005 & 0.2 & 0.25 & 0.25 & 0.3 & 0.55 & 1.6 & 5.0 \\
\hline$I_{w}\left(M W / \mathbb{m}^{2}\right)$ & - & - & - & - & - & 3.5 & 0.55 & 19.5 & 3.0 \\
\hline$I_{3}\left(M W / m^{2}\right)$ & 1 & $1.5-5$ & 1 & 5 & 5 & 0.87 & 0.87 & 4.8 & 4.8 \\
\hline $\mathrm{P}_{\mathrm{TH}}$ (MWt) & - & - & - & .. & - & 350 & 80 & 3350 & 1000 \\
\hline$T_{1}($ kev $)$ & 0.3 & $0.8-1.0$ & $1-2$ & $1-2$ & $4-6$ & $10-20$ & $20-30$ & $10-20$ & $20-30$ \\
\hline$\beta_{\theta}$ & $0.1-0.2$ & $0.1-(1.2$ & $0.1-c .2$ & $0.1-0.2$ & $0.1-0.2$ & 0.2 & 0.2 & 0.2 & 0.2 \\
\hline $\mathrm{mt}_{\mathrm{E}}\left(10^{20} \mathrm{~s} / \mathrm{m}^{3}\right)$ & $5(10)^{-5}$ & $2-8(10)^{-4}$ & $0.01-0.04$ & $0.01-0.04$ & $0.07-0.2$ & 1.0 & $10 . n$ & 1.0 & 10.0 \\
\hline
\end{tabular}

for construction to start in FY 86, it will come on-line in FY 90. In addition to extending the scaling results to the 2-MA level and testing current drive principles, this device will have the following scientific objectives: 27

1. Increase the values of plasma energy confinement time, temperature and density and determine how these parameters scale with plasma dimensions and current.

2. Achieve high current operation and ohmic heating to higher, reactor relevant plasma conditions.

3. Implement impurity control and wall protection to improve energy confinemeat .

4. Demonstrate oscillating field current drive under high temperature, high current conditions.

5. Confirm modes of RFP operation which have been demonstrated in ZT-4OM and ZT-P (see following paragraph), ramping of plasma current from a low current RFP discharge, and shell-less operation. 
The engineering objectives are:

1. Design and operate a robust, reliable, high current RFP experiment.

?. Design and implement wall protection and impurity control using limiters, pumped limiters, divertors, and high temperature liner conditioning.

3. Minimize field errors from liner, shell, and coils while maintaining diagnostic, experimental and repair access.

4. Provide the ability to test RFP operation as noted in items 4 and 5 of the scientific objectives.

To facilitate the design of $\mathrm{ZT}-\mathrm{H}$, a small, high-current density air core machine (ZT-P) has been constructed at Los Alamos. It has been providing information concerning air core operation since late 1984. ZT-P will be utilized to study the operation of RFPs with a variety of conducting shells as well as with a nonconducting shell. This device has been designed for minimum field errors so that the effect of appiied field errors on the confinement physics can be investigated. ZTT-P will be utilized to study the limjter/divertor/first wall problens associated with reactor reievant current densities $\left(10.5 \mathrm{r}^{\prime}: / \mathrm{m}^{2}\right)$ and loadings $\left(3.9 \mathrm{MW} / \mathrm{m}^{2}\right)$.

A summary of relevart parameters for ZT-P, ZT-40M, and ZT-H is given in Table VI. The parameters have been estimated for ZT-H with a $0.40-m$ minor radius and a 0.25-m minor radius. The parameters labeled with an asterisk reflect the changes which occur due to increases in the operating density.

TABLE II

ESTIMATED PARAMETERS FOR RFPS AT LOS ALAMOS

\begin{tabular}{|c|c|c|c|c|c|c|c|c|}
\hline & $\begin{array}{c}\text { Current } \\
\text { MA } \\
\end{array}$ & $\begin{array}{c}\text { Current } \\
\text { Densi ty } \\
\mathrm{MA} / \mathrm{m}^{2} \\
\end{array}$ & $\begin{array}{l}\text { Major } \\
\text { Radius } \\
\text { (m) }\end{array}$ & $\begin{array}{l}\text { Minor } \\
\text { Radius } \\
\text { (m) }\end{array}$ & $\begin{array}{l}\mathrm{T}_{\mathrm{e}} \\
(\mathrm{keV})\end{array}$ & $\begin{array}{l}\tau_{E_{1}} \\
\text { (ms) }\end{array}$ & $\begin{array}{l}\text { Wall } \\
\text { Loading } \\
\left(\mathrm{MW} / \mathrm{m}^{2}\right)\end{array}$ & $\begin{array}{c}\text { Current } \\
\text { Duration } \\
\quad(\mathrm{ms}) \\
\end{array}$ \\
\hline $\mathrm{ZT}-\mathrm{P}$ & 0.14 & 10.5 & 0.45 & 0.068 & 0.28 & $\sim 0.06$ & $\sim 11.5$ & $\sim$ \\
\hline $\mathrm{ZT}-40 \mathrm{M}$ & $\begin{array}{l}0.20 \\
0.60\end{array}$ & $\begin{array}{l}1.7 \\
5.0\end{array}$ & $\begin{array}{l}1.14 \\
1.14\end{array}$ & $\begin{array}{l}0.197 \\
0.197\end{array}$ & $\begin{array}{l}0.20 \\
0.60\end{array}$ & $\begin{array}{l}0.32 \pm 0.15 \\
\sim \quad 1.7\end{array}$ & $\begin{array}{l}\sim 1.7 \\
\sim 2.9\end{array}$ & $\begin{array}{l}\geq 25 \\
\geq 25\end{array}$ \\
\hline $\mathrm{ZT}-\mathrm{H}$ & 2.00 & 4.0 & 2.15 & 0.40 & $\begin{array}{l}2.00 \\
1.00 *\end{array}$ & $\begin{array}{l}\sim 42 \\
\sim 15^{*}\end{array}$ & $\begin{array}{l}0.6 \\
1.8^{\star}\end{array}$ & 50 \\
\hline $\mathrm{ZT}-\mathrm{H}$ & 2.00 & 10.2 & 2.15 & 0.25 & $\begin{array}{l}2.00 \\
1.30\end{array}$ & $\begin{array}{l}\sim 16 \\
\sim\end{array}$ & $\begin{array}{l}\sim 2.6 \\
\simeq 5.0^{*}\end{array}$ & 50 \\
\hline
\end{tabular}


2. First Wall Design. ${ }^{16}$ A schematic drawing of the Compact Reversed-Field Pinch Reactor (CRFPR) is shown in Fig. 5. This plasma is contained within a separate $20-\mathrm{mm}$ thick first wall shell composed of a water-cooled copper alloy (MZC/AMAX). The heat-transfer surface consists of 774 coolant tubes (24-mm diameter, 3-mm thick) encircling the minor circumference of the plasma. These tubes must withstand an average surface heat flux of $5 \mathrm{MW} / \mathrm{m}^{2}$, are designed to operate at heat fluxes as high as $9 \mathrm{MW} / \mathrm{m}^{2}$, and are capable of withstanding $10^{6}$ thermal cycles during the structure lifetime. Subcooled water at $8.3 \mathrm{MPa}$ (1200 psia), flowing at $10 \mathrm{~m} / \mathrm{s}$ enters the iirst-wall shell at $423 \mathrm{~K}$ and exits at $503 \mathrm{~K}$, resulting in a maximum local structural temperature of $590 \mathrm{~K}$. The characteristics of this first-wali design are given in Table VII.

TABLE VII

ENGINEERING PARAMETERS FOR CRFPR FIRST-WALL DESIGN

Composition: $60 \mathrm{v} / 0 \mathrm{AMAX} \mathrm{Cu}(\mathrm{MZC}, 0.06 \% \mathrm{Mn}, 0.15 \% \mathrm{Zr}, 0.4 \% \mathrm{Cr}$ by weight) 40 vio $\mathrm{H}_{2} \mathrm{O}$ (Coolant)

\begin{tabular}{|c|c|}
\hline Overall thickness (mm) & 20 \\
\hline Total íirst-wall mass (tonne) & 31 \\
\hline Number of coolant tubes facing plasma & 774 \\
\hline Tube length/diameter/wall thickness ( $\mathrm{mm}$ ) & $243 / 24.3 / 3.0$ \\
\hline Subcooled water pressure ( $\mathrm{MPa} / \mathrm{psia}$ ) & $8.27 / 1200$ \\
\hline Coolant velocity $(\mathrm{m} / \mathrm{s})$ & 10.3 \\
\hline Inlet/cutlet/maximum wall temperature $(K)$ & $423 / 503 / 590$ \\
\hline Average/maximum design surface heat flux $\left(\mathrm{MW} / \mathrm{m}^{2}\right)$ & $5.0 / 9.0$ \\
\hline Average power density $\left(\mathrm{MW} / \mathrm{m}^{3}\right)$ & 200.0 \\
\hline Maximum dpa/yr & 220.0 \\
\hline Average transmutation rates $\mathrm{Ni} / \mathrm{Zn}(\% / \mathrm{yr})$ & $2.6 / 2.2$ \\
\hline Electrical resistivity increase $(\% / y r)$ & $100-200$ \\
\hline
\end{tabular}


3. Limiter/Divertor/Impurity Control. The development, operation, and empirical characteristics of limiter/divertor systems in tokamaks, are well documented. In current RFP experiments limiters have been used sparingly and no experimental work has been done on divertors for these devices. If the magnetics associated with adding limiter/divertor systems to the RFP do not introduce plasma equilibrium or stability problems, the PMI and HHF issues for the RFPK (LPD) devices are essentially the same as the issues for tokamaks. The higher first-wall thermal loads associated with HPD operation may require that a large fraction of the first-wall serve as the limiter or be covered by limiter components. The edge regions of the plasma must be contıolled so tinat the plasma materials interactions occur reproducibly over large distributed areas. This first-wall/plasma interaction and associated sputter erocin key plasma engineering issues Enr the HPD systems. High density gas blankets in combination with divertor or pump limiters will be necessary to control impurities in the long pulse devices. The degree of applicability of divertor configurations to RFPs is closely connected to the question of whether an RFP configuration must have a quasi-zontinuous conducting shell for stability.

A recent study ${ }^{1,16}$ examined the possibility of using pumped limiters in the CRFPR. For plasma-edge conditions that allow $90 \%$ of the ohmic and alpha-particle power generated within the plasma to be radiated uniformly to the first-wall/limiter surfaces, 24 poloidal pumped limiters covering $30 \%$ of the first-wall area would allow $21 \%$ of the plasma particle loss "O flow into the liniter slot while maintaining the energy density onto the limiter leading edge below $6 \mathrm{MW} / \mathrm{m}^{2}$. The plasma-edge models have not yet been develuped suffiriently to permit accurate estimate of sputter erosion, although this, rather than heat-transfer per se, is viewed as ihe premier first-wall/limiter problem. Immediately behind this first-wall/pumped-limiter section would be a "second wail", defining with the first-wall a vacuum plenum; this plenum connects to a vacuum enclosure by a radial inner-blanket duct positioneci in the equatorial plane on the outboard side of the torus. Eliminating this second wall in favor of radial ducts which cut through the blanket in the minor circumference behinu each limiter is also being explored. The engineering parameters for this pump limiter scheme are given in Table VIII. 
TABLE VIII

\section{ENGINEERING PARAMETERS FOR PUMP LIMITER ¿YSTEM}

$\begin{array}{ll}\text { Configuration } & \text { Poloidal } \\ \text { Number of limiters, } \mathrm{N} & 24 \\ \text { Edge-plasma recyse, } \mathrm{R}_{\mathrm{L}}^{*} & 0.95 \\ \text { Fraction plasma energy loss radiated, } \mathrm{f}_{\mathrm{RAD}} & 0.90 \\ \text { Design heat flux onto limiter, } \mathrm{q}_{\mathrm{D}}\left(\mathrm{MW} / \mathrm{m}^{2}\right) & 6.0 \\ \text { Limiter coverage fraction, } \mathrm{I}_{\mathrm{L}} /\left(\mathrm{I}_{\mathrm{L}}+\mathrm{l}_{\mathrm{w}}\right) & 0.31 \\ \text { Toroicial exient of limiter, } \mathrm{l}_{\mathrm{L}}(\mathrm{m}) & 0.35 \\ \text { Fraction particles under limiter, } \mathrm{f}_{\mathrm{F}} & 0.21 \\ \text { Fraction energy under limiter, } \mathrm{f}_{\mathrm{E}} & 0.13\end{array}$

4. Conducting Shell. The equilibrium conditions may be provided by either externally applied vertical fields, a conducting toroidal sheil, or some combination of both. The RFP may require a conducting shell to statilize MHD modes with wavelengths longer than the shell radius. As the magnetic fields diffuse into the conducting shell, the plasma equilibrium and stability will change. Feedback control will be wecessary for the steariy-state (long pulse) devices. A careful assessment of the critical features and paramerers of the conducting shell is necessary. The introduction of pump limiters and diveitors may necessitate the removal of large segments of the shell, and the current experience on $Z \mathrm{Z}-4 \mathrm{UM}$, OGTE and $\mathrm{HBTX}-1 \mathrm{~A}$ is that major equilibrium problems can occur in the region of poloidal gaps without feedback control. The field errors cue to holes and/or gaps in the conducting shell may promote the development of stochastic field lines and magnetic islands in the outer edge of the plasma. A major goal of the current programs is to evaluate the effect of field errors and to determine adequate means of correcting the errors. 
1. Introduction. OHTE is a privately-funded (Phillips Petroleum Company and GA lechnologies under Joint Research and Development Agreemen I) experiment. It is a toroidal magnetic ccnfinement system with helical symmetry. The polojial and toroidal fields are comparable and the rotational transform and sher $r$ are provided by helical coils that encircle the torus. Stability is provided by magnetic shear coupled with a conducting shell. The device operates ar. low $q$, where $q$ is the safety factor at the plasma boundary; therefore, the plasma current can be utilized to ohmically heat the plasma. No auxiliary heating methods are required. As with other helical configurations, OHTE possesses a helical separatrix. The plasma is bounded by the separatrix which serves as a magnetic limicer.

The current emphasis of the program is tu develop the physics base necessary to asse'ss the potential of the OHTE concept for use as a high power density (HPD) reactor. A decision will be made in 1985 concerning the construction of the next device. The reactor operating conditions are similar Lo those of the CRFPR; however, the additional recirculating power required to chive the OHTE coils and the decrease in Tritium breeding resulting from the displacement of the blanket by the helical coils require more fusion power than the CRFPR for equivalent output power.

2. Limiter/Divertor/Impurity Control. The PMI and HHF issues associated with the OHTE device are similar to the issies for the RFP, with one major exception, the first wall thermal load. A typical OHTE configuration ${ }^{9}$ has three magnetic divertor areas. With LPD operation the PMI and HHF issues associated with ihese diveitors will be the same as for tokamaks, while the HFD operaition will be much more demanding than for tokamaks and somewhat more demanding than for the CRFPR due to the focussing of the particle flux. Divertor chambers capable of handling the power and particle loads will. have to be incorporated into the design of future devices. External separatrix placement, divertor chambers, and high-Z seeding of the plasma boundary to enhance radiation are being considered as means of mitigating this problem. In the near term; to reach optimum performance in the current OHTE device, the interaction of the plasma with the first wall in the area of the magnetic divertors may have to be controlled. 
In principle the Riggatron is a tokaniak; however, the combined use of high toroidal current density $\left(8 \mathrm{MA} / \mathrm{m}^{2}\right)$ and high magnetic fields (16-20T) provides a $q>2$ high-beta $(0.15-0.25)$, ohmically heated tokamak of the HPD type. The FPC would have a limited life ( -1 month) and would be completely replaced at frequent intervals. An examination of the parameter space leads to major radii in the range $0.57-0.95 \mathrm{~m}$ with aspect ratios of $2.0-2.5$. A major consideration is the first-wall heat flux of $20-40 \mathrm{MW} / \mathrm{m}^{2}$ and no use of divertors. The burn is terminated by impurity buildup after $-30 \mathrm{~s}$. The large magnetic fields, the high first-wall heat flux, and the thermal cycling of the system components are obvious problems. Current experiments do not operate at these high-betas (0.15-0.25), and routine operation in this "second stability" regime in $0 H$ lokamaks, with or without auxiliary heating, has not been demonstrated.

\section{E. $S / T / H^{26}, 28-31$}

1. Introduction. The $\mathrm{S} / \mathrm{T} / \mathrm{H}$ is a toroidal device which utilizes rested magnetic flux surfaces similar to those in a tokamak, to confine the plasma. In a tokamak the helical rwist (transfo:m) of the magnetic field lines which form these surfaces is partially genereted by toroidal plasma currents, but in a stellarator $i t$ is produced by twisting the external field coils. This arrangement of coils eliminates t'e need for externaliy driven plasma currents and allows a discuption-free, steady-state operation without the need for current drive.

Experiments on Wendelstein VII-A have produced ion temperatures of $\sim 1.0 \mathrm{keV}$ and Lawson numbers of $\geq 2 \times 10^{12} \mathrm{~cm}^{-3} \mathrm{~s}$ where $\tau_{\mathrm{E}} \sim 15 \mathrm{~ms}$. The LPD reactor extrapolations for stellarators are similar in size and energy density to the tokamak. Recent theoretical stucies indicate a "second stability regime" where operation at high beta $(\langle\beta\rangle \geqslant 8 \%)$ is possible. The corresponding reduction in size and increase in power density could provide a HPD option.

The goals of the stellarator program are to advance the physics understanding of toroidal confinement systems and to contribute to the development of superior reactor systems. The similarities between the tokamak 
and stellarator have resulted in the inclusion of the stellarator into the toroidal program plan.

A major effort in the stellarator program will be the ATF-1 experiment at ORNL which should begin operation in FY 86. This facility has been designed to allow access to the "second stability regime," with average betas (predicted by codes) as high as $8 \%$. Neutral beam injection (4.5 $\mathrm{MW}, 35 \mathrm{kV}$, $250 \mathrm{~ms}$ ) will be the primary heating system. ICRF systems capable of 2 MW are planned for a ater date. Reference 28 contains more information on ATF-1.

Most of the problem areas for the S/T/H (LPD option) are the same as for the tokamak, and if a HPD option proves to be possible, the problem areas will be similar to those for the OHTE and CRFPR. The three-dimensional helical character of $\mathrm{S} / \mathrm{T} / \mathrm{H}$ presents some added engineering difficulties.

2. First-Wall Design. A Modular Stellarator Reactor (MSR) conceptual design study ${ }^{1}$ has produced a credible first-wall/blanket maintenance approach that does not require routine coil movement. A sector of this reactor torus is shown in Fig. 6. The MSR-IIB fixed coil set surrourds a permanent vacuum boundary, which is penetrated by access hatches through which blanket/shield modules are inserted or removed. A typical module orientation is s'lown in Fig. 7 .

The first-wall/blanket sinield (FW/B/S) cross section is il?ustrated in Fig. 8. The clanket consists of a PCASS (Primary Candidate flloy Stainless Steel) structure and $\mathrm{Li}_{2}$ v solid breeder natrix with imbedded pressurized-water (15 MPa, $\mathrm{T}_{\text {IN }}=550 \mathrm{~K}, \mathrm{~T}_{\text {OUT }}=590 \mathrm{~K}$ ) coolant tubes. A helium purge stream removes tritium from the blanket. The cross section accommodates the elongated $1=2$ plasma cross section at the expense of thin beryllium neutron reflector regions at the ends of the plasma semimajor axis, covering 25\% of the available FH surface area. The plasma chamber opening within each module has a quasi-rectangular cross section and is cut straight through the module. The opening tracks the helical precession of the plasma cross section by a stepped $\left(\sim 7^{\circ}\right)$ poloidal rotation of the openings of successive modules. A typical center module (one of three per access port, 108 total) is illustrated in Fig. 9. The movable module mass is $\sim 60$ tonnes. 
3. Auxiliary Components. The auxiliary components, such as neutral beams and ICRH hardware, for the S/T/H are of the came type as being developed for the mainline programs.

4. Limiter/Divertor/Impurity Control. Impurity control for the ATF-1 is provided by a 5 to $10 \mathrm{~cm}$ scrape-off layer which shields the plasma core from the influx of edge neutrals. Impurity transport and the means to control it will be important areas of research. Certainly, for longer pulse machines pump limiters or divertor systems will have to be incorporated into the devices to control the impurities. These systems must adapt to the helical symmetry. A HPD option would have limiter/divertor/impurity control issues similar to those for the OHTE device. The MSR-IIB pumped-limiter 1 surface is subjected to $-2.5 \mathrm{MW} / \mathrm{m}^{2}$ of average incident radiation and particle flux.

The inclusion of limiter/divertors into $\mathrm{S} / \mathrm{T} / \mathrm{H}$ systems will require an evaluation of the affects of these components on the plasma equilibrium and stabi?ity. For example, the introduction of a limiter should not jnterrupt the flow of the Pfirsch-Schluter currents that result in the deepening of the magnetic well with increasing beta.28 Do currents flow in the scrape-off plasma layer? If so, what is the effect of these currents on the plasma equilibrium and stability? If these currents are forced to flow in a different mannex, do they affect the plasma characteristics?

F. $\quad{\underline{\mathrm{EBT}} / \mathrm{NBT}^{32}}^{2}$

i. Introduction. The EBT concept is a toroidal array of simple mirrors combined with an $r f$-gerierated, low density, energetic electron ring positioned between each of the mirror coils, which stabilizes the bulk toroidal plasma against simple mirror instabilities. Tris concept provides a steady-state, high beta $(\sim 0.17)$ system. A reactor study based on the EBT concept has been pubisished. 32

The dominant loss mechanisms from the toroidal plasma other than plasma energy and particle loss due to instabilities are the result of diffusive processes and unconfined particle orbits. An analysis of the EBT transport processes gives a scaling of the Lawson parameter: $n \tau_{p}$ increases with cemperature to the $3 / 2$ power and with the square of the magnetic aspect ratio. The EBTR design study resulted in a high aspect ratio $(\sim 35)$ device, vith a temperature of $\left(\mathrm{T}_{\mathrm{j}} \sim 28 \mathrm{keV}\right)$, a density of $0.95 \times 10^{14} \mathrm{~cm}^{-3}$, and a betal of 
0.17 with a surface heat flux of $-0.35 \mathrm{Mw} / \mathrm{m}^{2}$. It should be noted that the transport losses were found to be very sensitive to accurate placement of the magnet coils. 32

2. First-Wall, Blanket, and Shield. ${ }^{32}$ The EBTR study uses a first-wall, blanket, and shield (FWBS) system design concept that is similar to that for the STARFIRE tokamak reactor design. ${ }^{3}$ The major differences between the two designs are the wall loading, the configuration of the FWBS, and the geometric arrangement of the magnet sets. Although these differences are significant, the EBTR design study benefited greatly from the in-depth analyses performed on FWBS systems for the STARFIRE studies.

The FWBS design approach uses a high-temperature, high-pressure water coolant for both the first wall and the tritium-breeding blanket. Water also couls the shield region, but the lower power density in the shield produces only low-grade heat; this low-grade heat is rejected via cooling towers.

Many tritium-breeding materials and concepts were considered and evaluated as part of the STARFIRE tokamak design. ${ }^{3}$ Ultimately, a solid breeder with a helium purge for tritium removal and water coolant was adopted for STARFiRE. This concept was also adopted by the EBTR study, although several blanket materials have been changed in order to achieve better performance. The use of the solid breeder $\mathrm{LiAlO}_{2}$ requires that a næutron multiplier be incorporated inboard of the tritium-breeding region. A neutron-reflecting region is also incorporated outboard of the breeding region. The shielding is similar to that of the STARFIRE design, but the shield configuration is adapted to the jpecific requirements of the EBTR configuration.

The need to lncate the toroidal field (TF) coils as close as possible to the plasma, together with the fact that the plasma is offset from the TF-coil center, puts a premium on reducing the inboard blanket and shield thickness directly under the TF coils. The design approach uses a thinner int rard blanket region under the $T F$ coil and a denser shielding material (i.e., tungsten) to maintain adequate neutron and gamma-ray shielding for the coils. A thicker but more economic shield configuration is used at the outboard side, where size (thickness) is not as crucial. To provide a uniform transition from inboard to outboard regions, this design uses a set of offset cylinders. The material arrangement in the midplane FWBS is similar to that shown in 
Fig. 10, except concentric cylindrial regions of thicknesses similar to those of the outboard coil-plane region are used. In this arrangement, the midplane region, between the coils, has a thicker tritium-breeding zone (high tritium breeding raiio) and a less expensive radiation shield; the coil-plane region is subbreeding and requires more expensive (compact) shielding materials. A net tritium breeding ratio of 1.06 is achieved by this arrangement. Figure 11 depicis this two-region blanket concept as viewed through a cross section in the EBTR equatorial plane. Hence, a two-region FWBS is used for each of the 36 sectors in EBTR. Each sector is comprised of two FWBS modules: a coil-plane module that emphasizes TF/ARE (aspect-ratio enhancement) coil shielding and a midplane module that emphasizes tritium breeding.

The first-wall material must be periodically replaced. This replacement can be accomplished either in situ, by working internal to the torus, or by modular replacement, with the refurbishment conducted remote from the reactor. The approach based on in situ repair portends many disadvantages, such as a time-consuming repair process, difficult quality control of coolant and helium-purge piping weldments, and congested access areas. The use of a replacement module allows shorter removal times with the more time-consuming refurbishment processes being accomplished at a remote location. If the shield is removed with the blanket, the blanket coolant piping that passes through the shield need not be disturbed, and the shielding around the pipes is less complex; a higher confidence level is thereby maintained. In the approach adopted, the removal of a FWBS module section located between the TF coils precedes the removal of a separate module located under the TF coils (Fig. 11). To assure the desired TF/ARE-coil alignment, the coil sets are not removed nor the alignment disturbed after the initial installation during construction.

To incorporate a pumped-limiter concept for impurity control, a high-conductance vacuum connection between the pumped-limiter and vacuum pumps is required. A possible method for making this connection uses a vacuum plenum situated between the blanket and the shield. To assure a high vacuum conductance, an acceptably large flow area (i.e., size of the plenum) is important. Only a small vacuum area is allowable in the sector beneath the TF coils. The midplane module, however, will accommodate a plenum region. The plenum is restricted on the inboard region by the ARE coils, but expansion in the outer region in the vicinity of the vacuum pumps is possible. 
3. Pumped-Limiter Design Summary. The system consists of two single-bladed limiters completely encircling the plasma poloidally at each of the 36 midplane locations. The limiters are composed of ten poloidal segments similar to tie one shown in Fig. 12. The segments have a 0.58-m poloidal length. Located at the juncture of the midplane and the coil-plane blanket modules, the blades face the midplane, as is indicated 1n Fig. 13. The limiter blade and the first wall form a $0.06-m$ wide slot that extends $0.3 \mathrm{~m}$ along the field lines to the neck of the limiter. The slot then widens to $0.10 \mathrm{~m}$ as it penetrates the blanket at the coil-plane/midplane juncture; this blanket penetration opens into a $0.37-\mathrm{m}$ average width plenum region between the blanket and the shield, as is shown in Fig. 14. The limiter is structurally mounted to the shield, lut can be moved radially in order to maintain the proper alignment and positioning of the individual segments with respect to the plasma. The liniter assembly is fabricated from stainless steel and is covered with a 1.0-mim thick Be coating to control erosioi.

The low plasma-edge temperature $(-0.1 \mathrm{keV})$, which is required in order to reduce the limiter heat flux and to enhance the limiter pumping probability, is provided through a combination of puffing small amounts of high-Z gas (Xe) into the plasma-edge region and the charge-exchange losses associated with edge-plasma recycle. The required Xe concentration $\left(n_{X e} / n_{D T}-1.4 \%\right)$ is sufficiently low to have a negligible effect on the electron-ring losses while simultaneously causing a significant amount of the core-plasma power loss $(\sim 360 \mathrm{MH})$ to be radiated to the wall from the edge plasma. This effect together with the charge-exchange loss $(\sim 100 \mathrm{MW})$ and the conduction to the front face of the limiter $(\sim 61 \mathrm{MW})$ reduces the edge-plasma temperature to the desired value of $\sim 0.1 \mathrm{keV}$, thereby lowering the maximum heat load on the limiter to $\sim 2.3 \mathrm{MW} / \mathrm{m}^{2}$. These conditions are crucial to the successful thermal-mechanical operation of the pumped-limiter concept.

The total limiter heat load, including the nuclear heating, is $300 \mathrm{MWt}$. This power is removed by low-pressure cooling water flowing at a rate of $1200 \mathrm{~kg} / \mathrm{s}$. The inlet temperature and pressure are $388 \mathrm{~K}$ and $2.1 \mathrm{MPa}$ (300 psia), and the outlet coolant conditions are $448 \mathrm{~K}$ and $1.7 \mathrm{MPa}$ (250 psia). The lower surface-heat loads and reduced thermal stress allow the use of stainless steel as the reference structural material. 
It is proposed to ameliorate the problem of limiter erosion through the continuous injection of $\mathrm{Be}(\sim 244 \mathrm{~kg} / \mathrm{yr})$ into the edge-plasma region. The injected $B e$, together with Be that is continually sputtered from the first wall, leads to a Be deposition rate on the limiter that balances the limiter erosion rate. In addition, the injection of Be results in a net accumulation of $72 \mathrm{~kg}$ of Be in each blanket/shield moduls over its 11.6-year operating lifetime. A similar analysis of the first wall leads to a net erosion rate of $0.22 \mathrm{~mm} / \mathrm{yr}$. The 2.6-mm thick Be coating on the first wall, therefore, should be sufficient to meet the design criteria of a 11.6-year operating lifetime for the bilanket module.

The preliminary calculations 32 utilizing pump limiters for impurity control have indicated positive results. These techniques need to be incorpora"ed into the current (EBT-S) and future (EBT-P) devices for evaluation.

4. RF Components. The EBT system utilizes lower hybrid (LH) plasma heating for startup. A tunable amplifier with a frequency range of $0.556 \mathrm{GHz}$ to $1.46 \mathrm{GHz}$ will have to be developed for the large power levels (420 $\mathrm{kW}, 192$ anplifiers for EBTR). The ECRH gyrotrons required for electron-ring formation'sustenance must supply a total of $120 \mathrm{MW}$ at $50 \mathrm{GHz}$ (200 $\mathrm{kW}$ per uni:; for EBTR. The EBT-S experiment is currently investigating the rf heating issues and future directions are dependent on their experimental results. The development of these rf sources is necessary for the mainline programs as well as EBT.

The :onitinuous use of large amounts of ECRH may necessitate the development of first-wall components with high electrical conductivity such as copper in order to minimize eddy current losses. In addition, the blanket, shield, vacuum ducts, cryopanels, and associated hardware will have to be shielded from the high power $\mathrm{rf}$. Localized heating of internal components exposed to the rf energy will have to be accommodated, and dissipative structures, such as graphite limiters (if used), will have to be eliminated. 
IV. SUMMARY OF CRITICAL PMI AND HHF ISSUES

A. Introduction

Many $O 5$ the PMI and HHF problems are the same for the AFCs and the mainline approaches, especially for systems of equivalent system power densities; therefor?, the PMI and HHF requirements of the AFCs will be discussed relative to the requirements of similar mainline and/or HPD components. The HPD options will be contrasted with a tabulation of the characteristics of components for the RFP, which is representative of the HPD concept. In general, the HPD concepts operate under more stressed conditions Lue to the higher levels of neutron, radiation, heat, and particle fluxes and attain their neutron and erosion lifetime fluences in a chronologically shorter lifetime. The high heat loads require that a substantial fraction of the first wall serve as the limiter or be covered by limiter components. This dual role, limiter and first wall, may impose additional restrictions on the designs.

The level of effort on AFCs has resulted in a data base (theoretical and experimental) which is often insufficient to address the PMI and HHF problems with the same rigor as they can be addressed for the tokamale or mirror concepts. A concept is considered an alternative if it offers an end product that is significantly different fron the mainline approaches; therefore, each concept will have some unique features. Although the experience and knowledge gained from the development efforts on the mainline programs will undoubtedly benefit the AFCs in some areas, the time scale for the development of the AFCs into viable energy producing schemes cannot remain the same as for the mainline programs. An example of this tuation is the compact Toroid Program. Although a well-designed program plan exists, the decision concerning the best formation scheme will not be made until 1989-90. Until then a large variety of methods for producing compact toroids will be investigated. Also, it should be noted that the degree of development of the reactor concept for a particular AFC reflects the funding and program history.

The problems associated with PMI and HHF are not long term issues for some AFCs. Current experimental devices (CTX, ZT-40M, HBTX-1A, and OHTE) operate near to the conventional reactor conditions in terms of plasma beta and heat flux for pulse durations of $\leq 25$ ins. Problems associated with HPD operation such as equilibrium, impurity control, and thermal stresses will 
have to be solved before optimum machine parameters an be obtained for the operating devices.

\section{B. Assessment}

1. Wall Conditioning. The wall conditioning techniques for the stellarator/torsatron/heliotron ( $\mathrm{S} / \mathrm{T} / \mathrm{H}$ ), reverse field pinch (RFP), OHTE, and spheromaks operated in the low power density (LPD) mode should be the same as for tokamaks. The high power density (HPD) systems will have to utilize large surface areas of graphite (coated or uncoated) or copper first walls due to the higher heat fluxes. The use of uncoated graphite may necessitate a completely different type of conditioning than stainless steel, Inconel, or copper. If HHF coatings are used, a method for in situ replacement of the coating will have to be developed for future devices. In order for ZT-40M, HBTX-1A and OHTE to operate routinely at their design current levels, passively cooled versions of advanced first wall components will have to be incorporated into the devices; therefore, the methods for conditioning the wall components will have to be addressed in the current machines. No new techniques should be required for "flagship" machines or "reactor" level devices unless unforeseen changes in first-wall materials are necessary for long pulse or continuous operation. Wall conditioning techniques that are under investigation are the same as for tokamaks and include:

1. Gettering ( $\mathrm{Ti}$ and $\mathrm{Cr}$ );

2. HHF coatings ( $\mathrm{SiC}, \mathrm{TiC}, \mathrm{W}$, Mo, etc.);

3. Glow Discharge Cleaning (GDC);

4. Taylor Discharge Cleaning (TDC);

5. Vacuum Baking $\leq 200^{\circ} \mathrm{C}$;

6. Operating at elevated wall temperatures $\left(\leq 300^{\circ} \mathrm{C}\right)$.

2. First-Wall Design. Some representative $A F C$ and tokamak devices are listed in Table IX with the estimated average first wall thermal load in $\mathrm{MW} / \mathrm{m}^{2}$ for three specific time frames, 0-3 years, 3-8 years, and "Reactor." Wherever possible, an estimate of the thermal load for a HPD option is also given.

Reactor concepts based on the FRC utilize plasmoids which translate through a burn region which has a resistive first wall and a flux conserving shell. The pulsed nature of this scheme results in a potential thermal fatigue problem for the first wall. 
WALL LOADINGS FOR PRESENT AND FUTURE DEVICES

Device

TFTR

ZT-40M (200 kA)

$\mathrm{ZT}-40 \mathrm{M}(500 \mathrm{kA})$

ZT-P

HBTX-1A

OHTE

FRX-C

CTX

ATF -1

Alcator DCT

TFCD (SC)

$\mathrm{ZT}-\mathrm{H}(0.40 \mathrm{~m}, 2.0 \mathrm{MA})$

$\mathrm{ZT}-\mathrm{H}(0.25 \mathrm{~m}, 2.0 \mathrm{MA})$

RFX

CCTX

MSR

EBTR

Starĩire

RFPR

SPH (PPPL) (Avg/peak)

CRFPR

OHTE

Riggatron

CTOR (Avg/peak)
Average First Wall

Thermal Loading (MW/ $\left.\mathrm{m}^{2}\right)$ Time Frame

\begin{tabular}{cc} 
LFD & - HPD \\
\hline 0.80 & $-\cdots$ \\
1.70 & -- \\
$\leq 2.90$ & -- \\
-- & -11.5 \\
$\leq 2.00$ & --- \\
$\leq 2.00$ & -- \\
$?$ & \\
$?$ & $10-100$ \\
0.600 & -- \\
0.300 & $-\cdots$
\end{tabular}

0.25

$-\cdots$

$3-8$ years

$\leq 2.00$

$\leq 5.00$

$\lesssim 2.50$

?

?

$0-3$ years

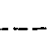

0.33

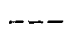

Reactor

0.35

0.90

0.68

?

$4.0 / ?$

$\cdots$

$\sim 5.00$

$-\quad-5.00$

-- 20-50

-- $\quad 2.0 / 5.8$ 
Some spheromak reactor scenarios involve translating the oblate configuration; however, an equilibrium cannot be maintained during the translation through a long-linear burn chamber.15 These equilibrium constraints lead to stationary spheromak reactors surrounded by a loosely fitted conducting sheil. The PMI and HHF characteristics of this first wall will be similar to those of the RFP.

For the RFP, a careful assessment of the critical features and parameters of the conducting shell is necessary. If the first wall must also be the conducting shell, additional complications may be imposed on the design. Wall armor and/or limiter components must be designed which are compatible with the plasma equilibrium and stability. The HPD systems will have to utilize large surface areas of graphite (coated or uncoated) or copper first walls due to the higher heat fluxes. If HHF coatings are used, a method for in situ reflacement of the cuating will have to be developed for future devices. Estimates for the HHF characteristics of the first-wall components required to take the HPD RFP to demonstration are given in Table $X$.

\section{TABLE X}

CHARACTERISTICS OF COMPONENTS - RFP

\begin{tabular}{|c|c|c|c|c|c|c|c|c|c|}
\hline$\frac{\text { Component }}{\text { MachIne It toe }}$ & Frame & $\begin{array}{l}\text { Noml nal } \\
\text { Heat } \\
\text { Flux } \\
\left(\mathrm{w} / \mathrm{cm}^{2}\right)\end{array}$ & $\begin{array}{l}\text { Conditions } \\
\text { Pulse } \\
\text { Length } \\
\text { (sec) } \\
\times 10^{-3}\end{array}$ & $\begin{array}{l}\text { Peak C } \\
\text { Heat } \\
\text { Plux } \\
\text { (H/cm }\end{array}$ & $\begin{array}{l}\text { Cond1tions } \\
\text { Pulse } \\
\text { Length } \\
\left.\mathrm{m}^{2}\right)(\mathrm{sec}) \\
\times 10^{-3}\end{array}$ & Coolant & $\begin{array}{l}\text { Typlcal } \\
\text { Material } \\
\text { Cholces }\end{array}$ & $\begin{array}{l}\text { S1ze } \\
\left(\mathrm{cm}^{2}\right) \\
\times 10^{4}\end{array}$ & $\begin{array}{c}\text { Number } \\
\text { of } \\
\text { Cycles }\end{array}$ \\
\hline
\end{tabular}

B1rat Wa11

\begin{tabular}{|c|c|c|c|c|c|c|c|c|c|}
\hline \multirow[t]{3}{*}{$0-3$ years } & 390 & $\leq$ & - & $\leq 3$ & Paestue & $\begin{array}{l}316 \text { SS } \\
\text { Incone } 1 \\
\text { Graph1te }\end{array}$ & 1.2 & -- & $\mathrm{ZT}-\mathrm{P}$ \\
\hline & 170 & 25 & -- & $\leq 10$ & Passive & $\begin{array}{l}316 \text { SS } \\
\text { Incone } 1\end{array}$ & 10.0 & - & $\begin{array}{l}\mathrm{ZT}-40 \mathrm{M} \\
\text { HBTX-1A }\end{array}$ \\
\hline & 290 & 25 & - & $\leq 10$ & & Graph1te & & & OHTE \\
\hline \multirow[t]{2}{*}{3 - 8 уеатв } & 60 & $\geq 250$ & - & $\leq 30$ & & $\begin{array}{l}316 \text { SS } \\
\text { Incone } 1\end{array}$ & 40.0 & -- & $2 \mathrm{~T}-\mathrm{H}(\mathrm{I})$ \\
\hline & 500 & 50 & -- & $\leq 30$ & Prosive & $\begin{array}{l}\text { Copper } \\
\text { Graph1te }\end{array}$ & 25.0 & & $R F X$ \\
\hline $9-14$ years & $\begin{array}{l}200 \\
500\end{array}$ & $\begin{array}{r}250 \\
\geq \quad 50\end{array}$ & - & $\begin{array}{l}\leq 30 \\
\leq 30\end{array}$ & & & $\begin{array}{l}35.0 \\
25.0\end{array}$ & -- & $\begin{array}{l}\mathrm{ZT}-\mathrm{H}(\mathrm{II}) \\
\mathrm{RFX}\end{array}$ \\
\hline $\begin{array}{l}\text { ETR } \\
\text { DEMO }\end{array}$ & $\begin{array}{r}87 \\
480\end{array}$ & S.S. & $\overline{900}$ & $5 . \overline{5}$. & $\begin{array}{l}\text { Sub- } \\
\text { Cooled } \\
\text { Water }\end{array}$ & $\begin{array}{l}\text { Copper } \\
\text { Alloy }\end{array}$ & $\begin{array}{r}56.0 \\
108.0\end{array}$ & $>\overline{10^{6}}$ & $\begin{array}{l}\text { ETR } \\
\text { DEMO }\end{array}$ \\
\hline
\end{tabular}


The wali loading for the EBT and LPD S/T/H are the same or less than for the tokamak. The three-dimensional helical character of the $S / T / H$ presents added engineering difficulties for the first wall, and the continuous use of large amounts of ECRH may ne essitate the development of first-wall components with high electrical conductivity for EBT.

3. Limiter/Divertor/Impurity Control. ${ }^{34,35}$ The operational characteristics of limiters and divertors are well known for tokamaks, however, it should be stressed that even with tokamaks, more consideration should be given to the distortion of the axisymmetry that results from the use of some limiter configurations. ${ }^{34}$ The current profiles in the scrape-off layer (SOL) can become strongly altered from the normal equilibrium profiles. The resulting change in the axisymmetric equilibrium conditions may result in a change in the plasma confinement properties.

Very little experimental or theoretical work has been done with limiters or divertors in the AFCs. As the duration of the experiments gets longer, the issues of plasma wall interactions and impurity control will become much more important. These issues may be responsible for the present difficulties in the devices operating with high thermal wall loadings $\left(\geq 1 \mathrm{MW} / \mathrm{m}^{2}\right)$ such as HBTX-1A, OHTE, CTX, and ZT-40M.

Current RFP experiments have begun to use limiters in an effort to protect the vacuum liner from the high heat loads. This work is in its infancy and extensive theoretical as well as experimental work will have to be actively pursued if the present generation devices are to operate routinely at their design current levels. The limiter systems will have to be designed so that they do not introduce plasma equilibrium or stability problems, and they will have to tolerate the high heat loads $\left(>100 \mathrm{MW} / \mathrm{m}^{2}\right)$ for short pulses ( $\leqq 25$ ms) without introducing impurities into the plasma system. Injection of gas into the boundary layer will be utilized in 2T-40M to study the effect on the plasma parameters in the edge plasma region and to investigate the time scales for impurity influx. Either pump limiters or divertors will have to be developed for use on the longer pulse devices ( $Z T-H$ and $R$ TX). An expertise will have to be developed to examine the impact of limiter/divertor systems on RFPs. Modeling of the edge plasma and evaluation of the equilibrium and stability of the plasma system are necessary elements for the appropriate design of these systems. 
APD operation will place even more stringent requirements on the limiter/divertor systems. A larger fraction of the wall will be involved in the interaction and very tight control of the plasma equilibrium and edge plasma parameters will be necessary. Even though the peak stresses may be higher for BPD operation, the solutions should logically result from extensions of technologies learred at the lower stress levels. Estimates for the characteristics of limiter components required to take an HPD RFP to demonstration are included in Table XI. Both pumped-limiter and magnetic divertor particle control schemes are being considered; however, more experimental and theoretical work has to be done before these designs can be finalized.

The limiter/divertor/impurity control issues for the OHTE device are very similar to those of the RFP discussed above. In the near term, the interaction of the plasma with the first wall in the area of the magnetic divertors may have to be controlled. Divertor chambers capeble of handling the power and particle loads will have to be incorporated into future devices.

TABLE XI

CHARACTERISTICS OF COMPONENTS - RFP

\begin{tabular}{|c|c|c|c|c|c|c|c|c|c|}
\hline$\frac{\text { Component }}{\text { Machine Time }}$ & Frame & $\begin{array}{l}\text { Nom1 nal } \\
\text { Heat } \\
\text { Plux } \\
\left(\mathrm{w} / \mathrm{cm}^{2}\right) \\
\times 10^{3}\end{array}$ & $\begin{array}{l}\text { Conditions } \\
\text { Pulse } \\
\text { Length } \\
(\text { sec) } \\
\times 10^{-3}\end{array}$ & $\begin{array}{l}\text { Peak Condiclong } \\
\text { Heat Pulse } \\
\text { Flux Length } \\
\left(\mathrm{W} / \mathrm{cm}^{2}\right)(\mathrm{sec}) \\
\times 10^{3} \times 10^{-3}\end{array}$ & Coolant & $\begin{array}{l}\text { Typlcal } \\
\text { Material } \\
\text { Cholces } \\
\end{array}$ & $\begin{array}{l}\text { S1ze } \\
\left(\mathrm{cm}^{2}\right) \\
\times \quad 10^{4}\end{array}$ & $\begin{array}{c}\text { Number } \\
\text { of } \\
\text { Cycles }\end{array}$ & References \\
\hline
\end{tabular}

Limlter

\begin{tabular}{|c|c|c|c|c|c|c|c|c|c|}
\hline \multirow[t]{3}{*}{0 - 3 years } & +11.5 & $\leq$ & 23.0 & 3 & Pasalve & Graphite & 0.12 & - & $2 T-P$ \\
\hline & +1.8 & $\leq 25$ & 3.6 & $\leq 25$ & Pasalve & Graphite & 0.94 & - & $\mathrm{ZT}-40 \mathrm{M}$ \\
\hline & +3.1 & $\leq 25$ & 6.2 & 25 & Pasalve & Graphite & 0.94 & - & $\begin{array}{l}\text { HBTX-1A } \\
\text { OHTE }\end{array}$ \\
\hline \multirow[t]{2}{*}{$2-8$ years } & +0.2 & $\geq 250$ & 0.8 & $\geq 250$ & $\begin{array}{l}\text { Passive } \\
\text { During }\end{array}$ & $\begin{array}{l}\text { Coated } \\
\text { Graphite, }\end{array}$ & 12.0 & - & $\mathrm{ZT}-\mathrm{H}(\mathrm{I})$ \\
\hline & +1.6 & $\geq 50$ & 6.5 & 50 & $\begin{array}{l}\text { Discharge } \\
\text { \& Active }\end{array}$ & $\begin{array}{l}\text { Bare } \\
\text { Graphite, }\end{array}$ & 8.0 & - & \\
\hline \multirow[t]{2}{*}{$9-14$ years } & $\begin{array}{r}+0.65 \\
+\end{array}$ & $\geq 250$ & 2.6 & $\geq 250$ & $\begin{array}{l}\text { (Water) } \\
\text { Between }\end{array}$ & $\begin{array}{c}\text { or } \\
\text { Copper }\end{array}$ & 11.0 & $\rightarrow$ & $2 \mathrm{~T}-\mathrm{H}(\mathrm{II})$ \\
\hline & +1.60 & 50 & 6.5 & 50 & Discharges & Alloy & 8.0 & - & \\
\hline $\begin{array}{l}\text { ETR } \\
\text { DEMO }\end{array}$ & $\begin{array}{l}0.11 \\
0.60\end{array}$ & $\begin{array}{l}\text { S.S. } \\
\text { S.S. }\end{array}$ & $\begin{array}{l}-- \\
--\end{array}$ & - & $\begin{array}{l}\text { Water } \\
\text { Water }\end{array}$ & $\begin{array}{l}\text { Copper } \\
\text { Alloy }\end{array}$ & $\begin{array}{l}17.0 \\
34.0\end{array}$ & - & $\begin{array}{l}\text { ETR } \\
\text { DEMO }\end{array}$ \\
\hline
\end{tabular}

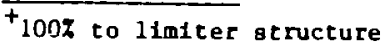

*90z uniformly distributed on limiter/first wall
} 
The RFP and OHTE HPD options require extensions of wall loading technology by factors of $\sim \times 5$ from conditions in the LPD options; however, the Riggatron requires exiensions of $\sim$ another factor of $\times 5$. At ine present time it is difficult to perceive the solutions to the impurity control and thermal stress problems resulting from heat fluxes as large as those projected for the Riggatron.

The three-dimensional helical character of the S/T/H presents added difficulties for the engineering of divertors or limiters which adapt to this helical symmetry. If a HPD option is identified, the problems would be similar to those for the OHTE device discussed above; otherwise, the problems should be similar to the tokamak.

The limiter/impurity control issues and solutions for the EBT concept are very similar to those of the mainline prograns.

Both the spheromak and the FRC have natural magnetic divertors. The PMI and $H H F$ issues will be the same as the mainline program where similar fusion power outputs produce heat flux problems similar to those which occur in the divertor chamber of a tokamak or the end cell of a mirror machine. HPD options will have correspondingly more heat flux and the divertor chamber will have to be designed accordingly. The spheromak approach ${ }^{20}$ utilizing electrodes for injection of magnetic helicity will have to develop or identify the technology necessary to prevent the injection of impurities from the electrodes.

4. Radioactivity Characteristics. The materials problems associated with integrated neutron dose produce a correspondingly shorter lifetime for the HPD system components than for the LPD system components. Neutron volumetric heating, swelling, hardening, and embrittlement are examples of this type of prublem. The ability to replace the entire FPC as a unit is a major asset of the HPD approach to fusion and should result in an overall higher plant availability and lower maintenance cost even though the FPC has to be replaced more often. Versions of the CT reactor (CTOR, TRACT, MRFRMR) can probably be constructed so that large "block" repiacement of the reactor components is possible, yielding a high plant availability. 
5. Auxilialy Components (RF, NBI, etc.). The need for the development of NBI and RF components for plasma heating and current drive is basically the same for some of the AFCs [S/T/H, EBT/NBT, CT (some concepts)] as for the mainline programs. Current drive for the RFP (ZT-H) iia F- $\theta$ pumping will use low frequency $(-1 \mathrm{kHz}$ for $\mathrm{ZT}-\mathrm{H}$ and $\sim 60 \mathrm{~Hz}$ for a reactor) components which should not require the development of new technology. A careful assessment of the critical features and parameters of the conducting shell for RFPs (ZT-H and ZT-P) will be of major importance with respect to design of the other PMI and HHF systems. The optimum method of plasma production, translation (if used), and heating for the CT concept will have to be identified and developed (CCTX).

6. Vaclium Systems. The LPD options of the AFCs have the same requirements for vacuum systems as the tokamak program. With tokamaks as with the AFCs, the use of large amounts of $r f$ power will require careful shielding of the vacuum system components from the rf energy.

The total vacuum and/or divertor pumping speeds will have similar requirements of both the HPD option and the LPD systems; therefore, the vacuum ducting may be a more dominant featur = relative to the FPC size for the HPD than for the LPD systems (including tokamaks and mirrors). This requirement, along with the requirement for a larger (fractional) volume for the primary coolant ducting, may generate a difficult "real estate" problem in the vicinity of the FPC for some concepts. Those approaches that place the FPC, or a portion thereof, within a vacuum envelope minimize this "real estaie" problem.

7. Fueling. Pellet refueling requirements for both the AFCs and the mainline programs are similar, as are the requirements for LPD and HPD systems. A pellet ablation scaling law that agrees with experiment ${ }^{36}$ indicates that the pellet lifetime is weakly dependent on average plasma density $\left(\propto 1 / n^{1 / 3}\right)$. The decrease in plasma radius for HPD systems more than compensates for the higher plasma density and results in similar or less stringent requirements on pellet velocity. Systems with similar energy outputs will require similar fueling rates; therefore, the pellet injection frequency should be the same as for the conventional systems. 
8. Plasma Equilibrium. The design of a limiter/divertor system should insure that the currents induced in the divertor/limiter structure or the modification of the plasma currents terminated by the structures do not generate problems with the global equilibrium or introduce toroidal asymmetries which interfere with the confinement. These effects have been conside-ed theoretically for tokamaks in certain circumstances; ${ }^{34}, 35$ however, very little experimental work has been done at reactor level beta (or plasma pressure) conditions. Due to the lower level of effort for AFCs, even less consideration has been given to these problems in AFCs.

An extensive effort to combine self-consistent models for the scrape-off layer with plasma equilibrium and plasma stability codes should be made. The effect of field errors due to gaps in the conducting shell or discrete winding configurations should be included. This is inherently a 3-D problem where departures from axisymmetry need to be accurately determined and modeled. Care must be taken to avoid gross plasma modes which cannot be stabilized by the high shear, conducting wall, or by the feedback systems. Again, there would be a considerable level of effort involved in the implementation of these considerations for the AFCs, and the manpower may not be available.

HPD operation will place stringent requirements on the interaction of the limiter/divertor systems with the plasma system. Control of the plasma equilibrium and edge plasma parameters will be necessary to prevent localized heat fluxes which exreed the design conditions.

9. Disruptions. The AFCs (EBT/NBT, S/T/H) which operate in a "currentless" mode are not expected to experience disruptions. The RFP, OHTE, High Field Tokamak and the CT schemes all have toroidal currents and can experience "current terminations." The collapse of the field structures in these devices dissipates the field energy and terminates the current flow in the plasma. The present experiments do not experience localized damage of the typa generated in tokamak disruptions. Once the disruption mechanisms are identified and understood for tokamaks the potential for similar behavior in the AFCs can be assessed. The differences in the field structures (relative to the tokamak) may preclude the occurrence of the "disruption" phenomena.

All operating RFPS (ZT-40M, HBTY-1A, and OHTE) experience an abrupt end to the discharge where the plasma current decreases rapidly to zero in a few hurdred microseconds. Accompanying the termination of the current is a 
positive pulse in the toroidal voltage at the liner, indicating that foloidal flux is entering the liner from the external circuit. A single-turn voltage in the range of 0.5 to $1.5 \mathrm{kV}$ occurs for plasma currents in the range of 80-200 kA in 2T-40M.25 No clear indication of any voltage scaling with current exists because some low current discharges can have high voltage spikes. The physics of MHD oscillations that occur in ZT-40M just preceding the current termination and their connection to the termination are being investigated. ZT-I and RFX with their Jigger physical size, lower field errors and better confinement times w:ll be very important in assessing "disruption" type phenomena in RFPs.

\section{Summary}

As discussed in the previous sections, many of the PMI and HHF probiems are similar for the AFCs and the mainline approaches, especially for systems of similar power densities. The AFCs do have some attractive features which could lead to lower cost and reduced development requirements. Plasma systems in which the plasma is confined in a near-minimum energy state (Taylor state) may be able to use magnetic helicity injection 20 or a low frequency "F- $\theta$ pumping"25 technique to drive steady-state currents. For those systems which rely on ohmic heating to ignition, the development of auxiliary heating components is not necessary.

The real promise of AFCs appears to be in the development of HPD systems.13,* For those systems that can operate efficiently (i.e., low recirculating power) at high neutron first-wall loading $\left(10-20 \mathrm{MW} / \mathrm{m}^{2}\right)$ with exo-blanket resistive coils, fusion-power-core (FPC) nower densities in the range of $10-15 \mathrm{MWt} / \mathrm{m}^{3}$ are possible. These HPD approaches may produce cheaper electricity while maintaining the reactor plant equipment as a minority part of the total direct cost. For a radiation life fluence of $15 \mathrm{MWyr} / \mathrm{m}^{2}$ (14.1-MeV neutrons) the $20-\mathrm{MW} / \mathrm{m}^{2}$ CRFPR system would operate for $0.75 \mathrm{full-}$ power years (FPY), or approximately one chronological year ( $75 \%$ plant factor) before changeout of the 45-tonne first-wal? and blanket system. If the 20-MW/m² HPD design can be technically achieved, a few (single?)-piece or "vatch" maintenance schenie may be pcssible, wherein a completely astsembled and

\footnotetext{
ॠInformation prcvided by R.A. Krakowski, Los Alamos National Laboratory Group CTR-12.
} 
pre-tested (thermally, hydraulically, electrically) first-wall/blanket/shield/toroidal-field-coil unit would be installed in the reactor hall after off-site fabrication and quality assurance. In addition, a possibility exists for a shortened initial construction and installation period, and the potential for a reduced mean-time-to-repair and more reliable reactor restarts can be traded off with the possibility of decreased mean-time-to-failure. High plant availability and reduced costs may be possible. This attribute and the related advantages associated with small, single-unit FPCs make the higher wall-loading designs attractive, in that the cost of electricity per se is a weakly diminishing function of wall loading above $\sim 10 \mathrm{MW} / \mathrm{m}^{2}$. A wide range of physics, engineering, and safety/environmental issues remains to be resolved, however, before the merits of these unique HPD approaches to fusion power can te fully assessed.

\section{REFERENCES}

1. R. A. Krakowski, "Identification of Future Engineering Needs of Alternative Concepts for Magnetic Fusion Energy," submitted to the Furure Engineering Development Needs for Magnetic Fusion Workshop, Washington, D.C., August 3-4, 1982. Los Alamos National Laboratory document LA-UR-83-1973.

2. C. C. Baker, C. A. Carlson, and R. A. Krakowski, "Trends and Developments in Magnetic Confinement Fusion Reactor Concepts," Nucl. Technol./Fusion 1, 5-78 (1981).

3. C. E. Wagner, "Possibility of Achieving Ignition in a High Field Ohmically-Heated Tokamak," Phys. Rev. Lett. 46, 654 (1981).

4. R. A. Krakowski, R. L. Miller, C. G. Bathke, R. L. Hagenson, A. S. Tai, C. E. Wagner, R. W. Bussard, R. A. Shanny, J. S. Herring, L. M. Lidsky, A. L. Cooper, D. J. Jenkins, Jim Pierre, E. P. Scannell, P. J. Turchi, N. K. Winsor, A. B. Barcilon, J. P. Boris, R. L. Burton, H. J. Willenberg, A. L. Hoffman, L. C. Steinhauer, P. H. Rose, "Reactor System Studies of Alternative Fusion Concepts," IAEA-CN-38/V4, Plasma Physics and Controlled Nuclear Fusion Research 1980, IAEA, Vienna, 1981, II, 607.

5. S. N. Rosenwasser, R. D. Stevenson, G. -istvinsky, D. L. Vrable, J. E. McGregor, and N. Nir, (to be published in Journal of Nuclear Materials), presented at 3rd Topical Meeting on Fusion Reactor Materials, Albuquerque, NM. September 19-22, 1983.

6. R. A. Jacobsen, C. E. Wagner, and R. E. Covert, (to be published in Journal of Fusion Energy). 
7. R. A. Jācobsen, R. E. Covert, P. Koert, G. Listv' ky, J. E. McGregor, N. Nir, S. N. Rosenwasser, R. D. Stevenson, D. L. Vrable, and C. E. Hagner, Invited Paper presented at IEEE $10 \mathrm{th}$ Symposium on Fusicn Engineering, Philadelphia, PA, December 5-9, 1983.

8. F. A. Puhn and C. L. Jackson, "The OHTE Confinement Test: An Engineering Overview," Proc. 4th Top. Mtg. Technol. of Controlled Nuclear Fusion, CONF-801011 II, 871, King of Prussia, PA (October 14-16, 1980).

9. R. F. Bourque, "OHTE Reactor Concepts," Proc. 9 th Symp. on Eng. Prob. of Fusion Research II, 1851, Chicago, IL (0ctober 26-29, 1981).

1). R. L. Hagenson, R. A. Krakowski, and H. Dreicer, "High-Power-Density Approaches to Magnetic Fusion Energy: Froblems and Promise of Compact Reversed-Field Pinch Reactors (CRFPR)," Stockholm Symp. on New Trends in Unconventional Approaches to Magnetic Fusion (June 16-18, 1982) to be published in J. Nucl. Instr. and Methods (1982). Also Los Alamos National Laboratory document LA-UR-82-1480.

11. R. L. Hagenson and R. A. Krakowski, "Compact Reversed-Field Pinch Reactors (CRFPR): Sensitivity Study and Design-Point Determination," Los Alamos National Laboratory report LA-9389-MS (July 1982).

12. R. L. Hagenson, R. A. Krakowski, "Engineering Design of a Compact RFP Reactor (CRFPR), 5th ANS Topical Meeting on the Technoloy of Fusion Energy, Knoxville: TN (April 26-28, 1983) Nucl. Tech/Fusion 4, No. 2, Part 3, 1284, and Los Alamos National Laboratory document LA-U $\bar{R}-83-932$, April 1983.

13. R. L. Hagenson, R. A. Krakowski, C. G. Bathke, R. L. Miller, M. J. Embrechts, N. M. Schnurr, M. E. Battat, R. J. LaBauve, and J. H. Davidson, "Compact Reversed-Field Pinch Reactors (CRFPR): Preliminary Engineering Considerations," Los Alamos National Laboratory report LA-10200-MS (August 1984).

14. R. L. Hagenson, R. A. Krakowski, R. N. Byrne, D. Dobrott, Plas. Phys. and Controlled Nucl. Fus. Res. (1982) Vol. I, IAEÁ, Vienna (1983) 373.

15. R. L. Hagenson, Proc. Fifth Symp. on the Phys. and Technology of Compact Toroids, Mathematical Sciences Northwest, Inc., Nov. 16-18, 1982, p. 157.

16. R. A. Krakowski and R. L. Hagenson, "Compact Fusion Reactors," 5 th ANS Topical Meeting on the Technology of Fusion Energy, Knoxville, TN (April 26-28, 1983) Nucl. Tech/Fusion 4, Part 3, 1265, and Los Alamos National Laboratory document LA-UR-83-932, April 1983.

17. R. A. Krakowski, J. E. Glancy, and A. E. Dabiri, "The Technology of Compact Fusion Reactor Concepts," submitted to National Science Foundation "Workshop in Compact Fusion Reactors," Washington, D.C., September 31-0ctober 1, 1982, Nucl. Tech/Fusion 4, No. 2, Part 1, 342, and Los Alamos National Laboratory document LA-UR- $8 \overline{2}-2994$. 
18. R. A. Krakowski, R. L. Miller, and R. L. Hagenson, "A Review of Alternative Concepts for Magnetic Fusion, 4 th ANS Topical Meeting on Technology of Controlled Nuclear Fusion, King of Prussia, PA (0ctober $14-17,1980$ ).

19. T. R. Jarboe, "Steady State Spheromak," Proc. Fifth Symp. on the Phys. and Technology of Compact Toroids, Mathematical Sciences Northwest, Inc., November 16-18, 1982, p. 169.

20. T. R. Jarboe, I. Henins, A. R. Sherwood, Cris W. Barnes, and H. W. Hoida, Phys. Rev. Lett. 51, 39 (1983).

21. D. B. Fradkin, A. W. Blackstock, D. J. Roehling, T. F. Stratton, M. Williams, and K. W. Liewer, AIAA J. $\underline{8}, 886$ (1970).

22. W. F. Dove, "Compact Toroid Development Status and Technical Needs," (DOE/ER-0160) February 1983.

23. R. L. Hagenson, R. A. Krakowski, "A Compact-Toroid Fusion Reactor Based on the Field-Reversed Theta Pinch," Los Alamos National Laboratory report LA-8758-MS, March 1981.

24. A. C. Smith, Jr., G. A. Carlson, K. R. Schultz, W. S. Neef, D M. Woodall, R. E. Price, F. S. Felber, C.P.C. Wong, K.Y.V. Chen, C. P. Ashworth, W. C. Condit, "Preliminary Conceptual Design of the Moving Ring Field-Reversed Mirror Reactor," Pacific Gas and Electric Company report 78FUS-1, August 1978.

25. Philip Thullen (compiler) "ZT-40U: Conceptual Design of a 2-MA Reversed Field Pinch Experiment," Los Alamos National Laboratory document LA-UR-83-1375, April 14, 1983.

26. R. C. Davidson, H. K. Forsen, L. Berry, R. F. Beuligmann, R. W. Conn, J. E. Cummings, T. K. Fowler, H. P. Furth, J. R. Gilleland, R. A. Gross, D. L. Kummer, R. K. Linford, P. Murray, M. N. Rosenbluth, A. Schriesheim, MFAC Report on Recommended Fusion Program Priorities and Strategy, September 1983.

27. R. L. Hagenson, R. A. Krakowski, G. E. Cort, "The Reversed-Field Pinch Reactor (RFPR) Concept," Los Alamos Scientific Laboratory report LA-7973-MS (August 1979).

28. 0. B. Adams, R. L. Brown, W. D. Cain, 3. A. Carreras, L. A. Charlton, W. A. Cooper, R. A. Dory, P. H. Edmonds, 0. C. Eldridge, A. C. England, R. H. Fowler, L. Garcia, D. Goodman, J. H. Harris, T. C. Hender, H, R. Hicks, S. P. Hirshman, D. J. Hoffman, S. Hokin, J. A. Holmes, R. C. Isler, T. C. Jernigan, R. L. Johnson, V. E. Lynch, F. F. Lyon B. F. Madsen, M. Murakami, G. H. Neilson, B. E. Nelson, J. A. Rome, M. J. Saltmarsh, J. Sheffield, P. B. Thompson, A. J. Wooton, "Proposal to Build ATF-1 An Advanced Toroidal Facility to Study Beta Limits and Low Collisionality Transport in a Current-Free Torsatron," Oak Ridge National Laboratory, Oak Ridge, Tennessee (October 1982). 
29. J. F. Lyon, V. E. Lynch, E. F. Masden, B. E. Nelson, J. A. Rome, "Magnetic Limiter/Divertor Studies for ATF-1," Symp. Energy Removal and Particle Control in Toroidal Devices, PPPL (26-29 July 1983).

30. R. L. Miller, C. G. Bathke, R. A. Krakowski, F. M. Heck, L. Green, J. S. Karbowski, J. H. Murphy, R. B. Tupper, R. A. Deluca, A. Moazed, and R. A. Terry, "The Modular Stellarator Reactor: A Fusion Power Plant," Los Alamos National Laboratory repurt LA-9737-MS (July 1983).

31. R. L. Miller, C. G. Bathke, R. A. Krakowski, F. M. Heck, L. Green, J. S. Karbowski, J. H. Murphy, R. B. Tupper, R. D. Deluca, A. Moazed, and R. A. Terry, "Modular Stellarator Reactor Conceptual Design Study," 5th ANS Topical Meeting on the Technology of Fusion Energy, Knoxville, TN (April 26-28, 1983) Nucl. Tech/Fusion 4, Part 3, 1308, and Los Alamos National Laboratory document LA-UR-83-9932, April 1983.

32. W. B. Ard, K. A. Barry, C. G. Bathke, D. A. Bowers, J. W. Davis, D. A. DeFreece, D. E. Driemeyer, D. J. Dudziak, L. Gise, S. Hamasaki, R. E. Juhala, R. J. Kashuba, B. C. Kenessey, H. H. Klein, R. A. Krakowski, D. W. Lieurance, J. A. de la Mora, J. L. Saunders, P. B. Stones, L. M. Waganer, and D. S. Zuckerman, "ElMo Bumpy Torus Reactor and Power Plant Conceptual Design Study," Los Alamos National Laboratory report LA-8882-MS (August 1981).

33. C. C. Baker (principal investigator), et al., "Starfire - A Commercial Tokamak Fusion Fower Plant Study," Argonne Nlational Laboratory report ANL/FPP-80-1 (September 1980).

34. R. W. Motley, Nucl. Fusion 21, 1541 (1981).

35. V. S. Mukhovatov, V. D. Shafranov, Nucl. Fusion 11, 605 (1971).

36. P. B. Pazks, R. J. Turnbull, and C. A. Foster, Nucl. Fusion 17, 3, 539 (1981). 

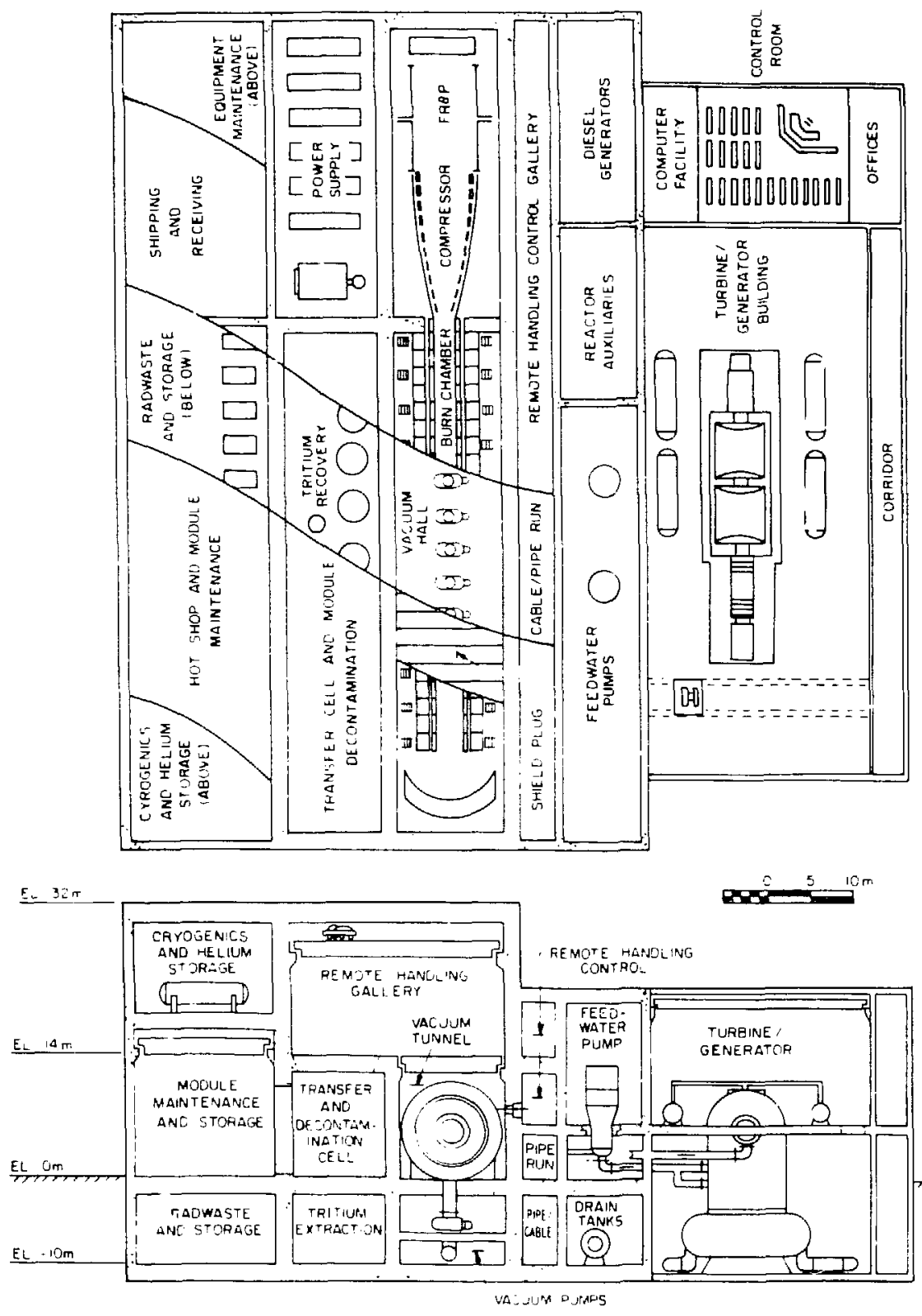

Fig. 1.

Preliminary plant layout for CTOR. 
COMPACT TORUS REACTOR (CTOR)

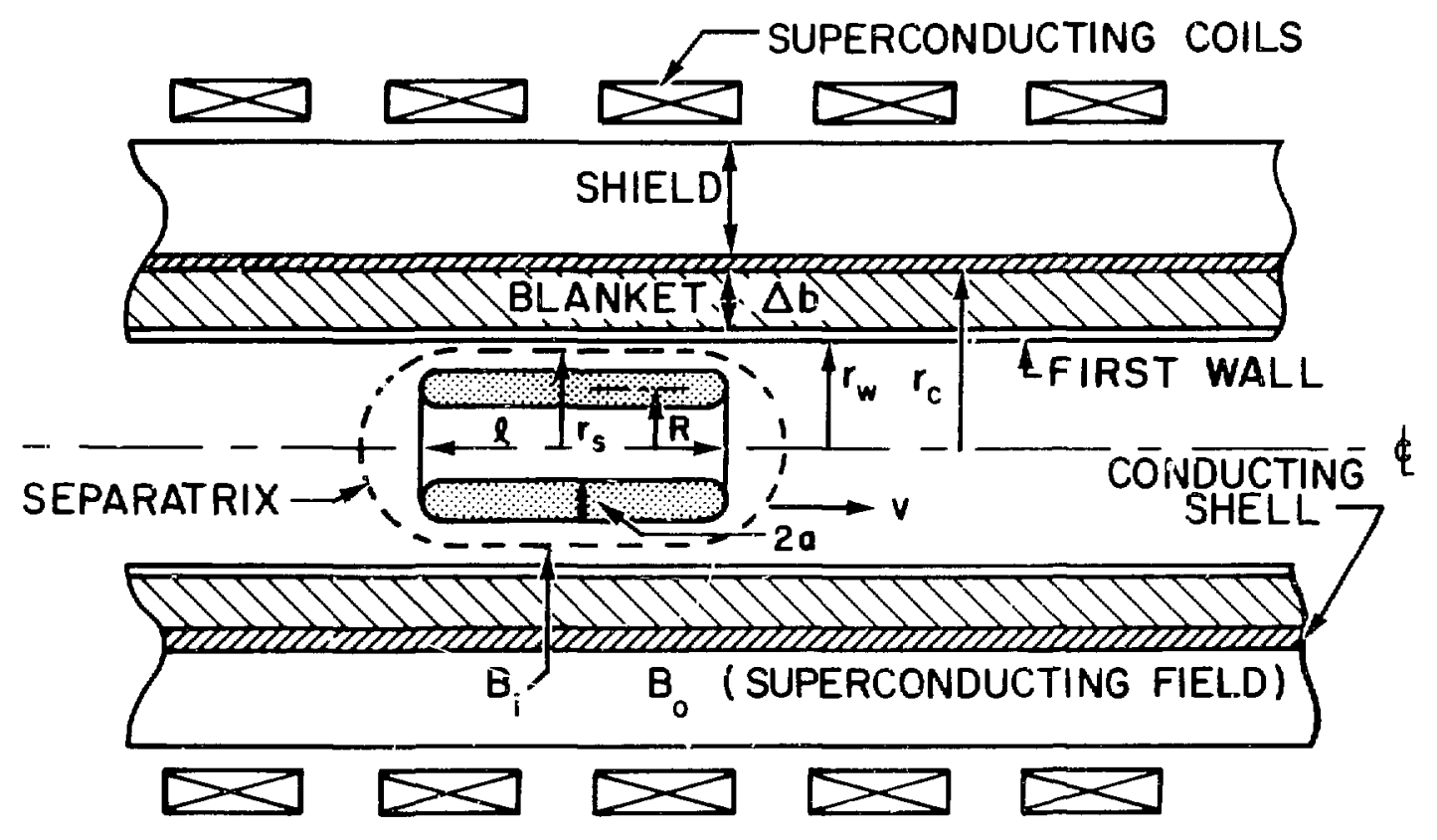

Fig. 2.

Schematic view of the Compact Toroid Reactor (CTOR) based on translating rielu-Reversed Theta Pinch. 


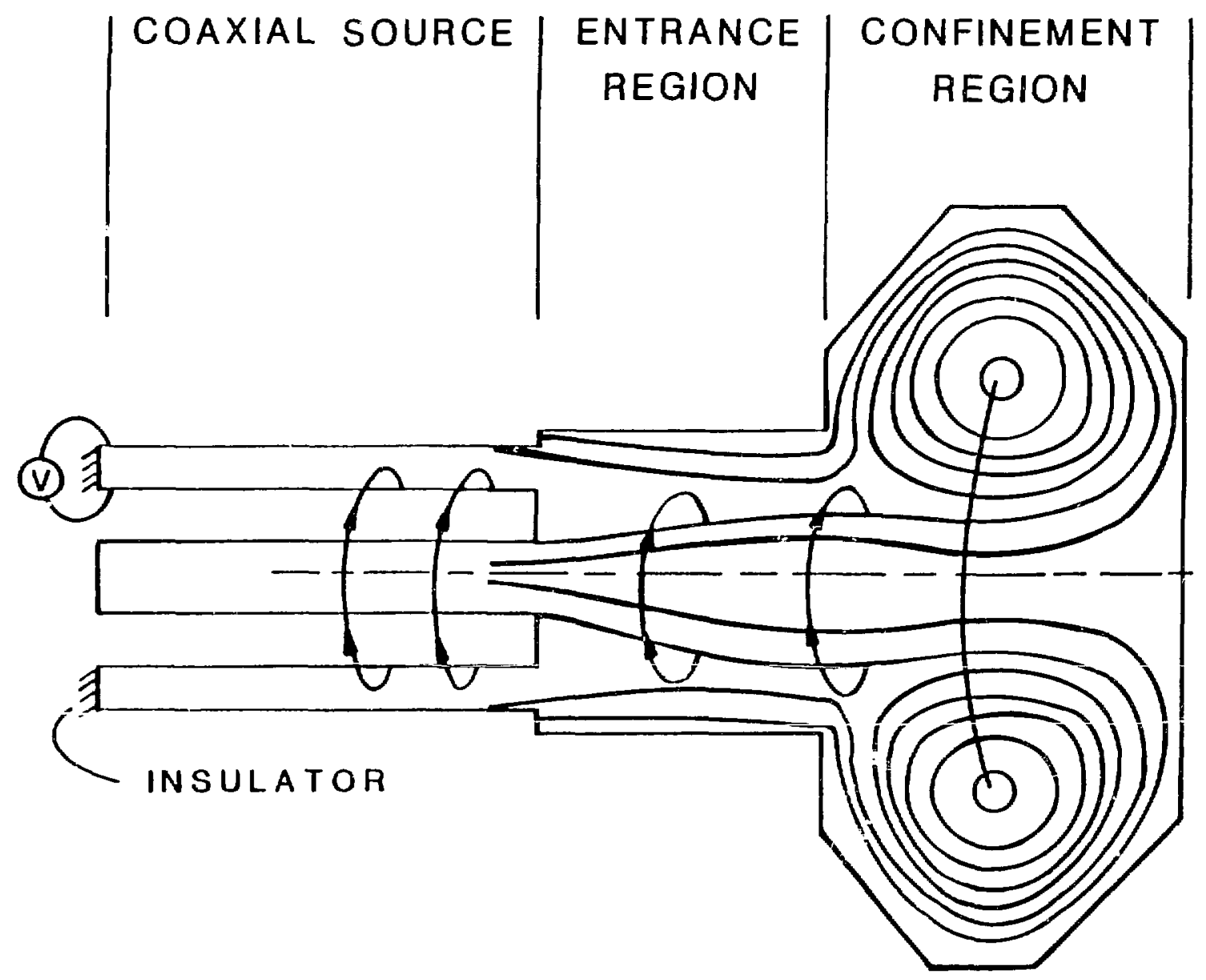




\section{REVERSED-FIELD PINCH PROGRAM SCHEDULE PROJECTIONS \\ CONSTRAINED BUDGET CASE}

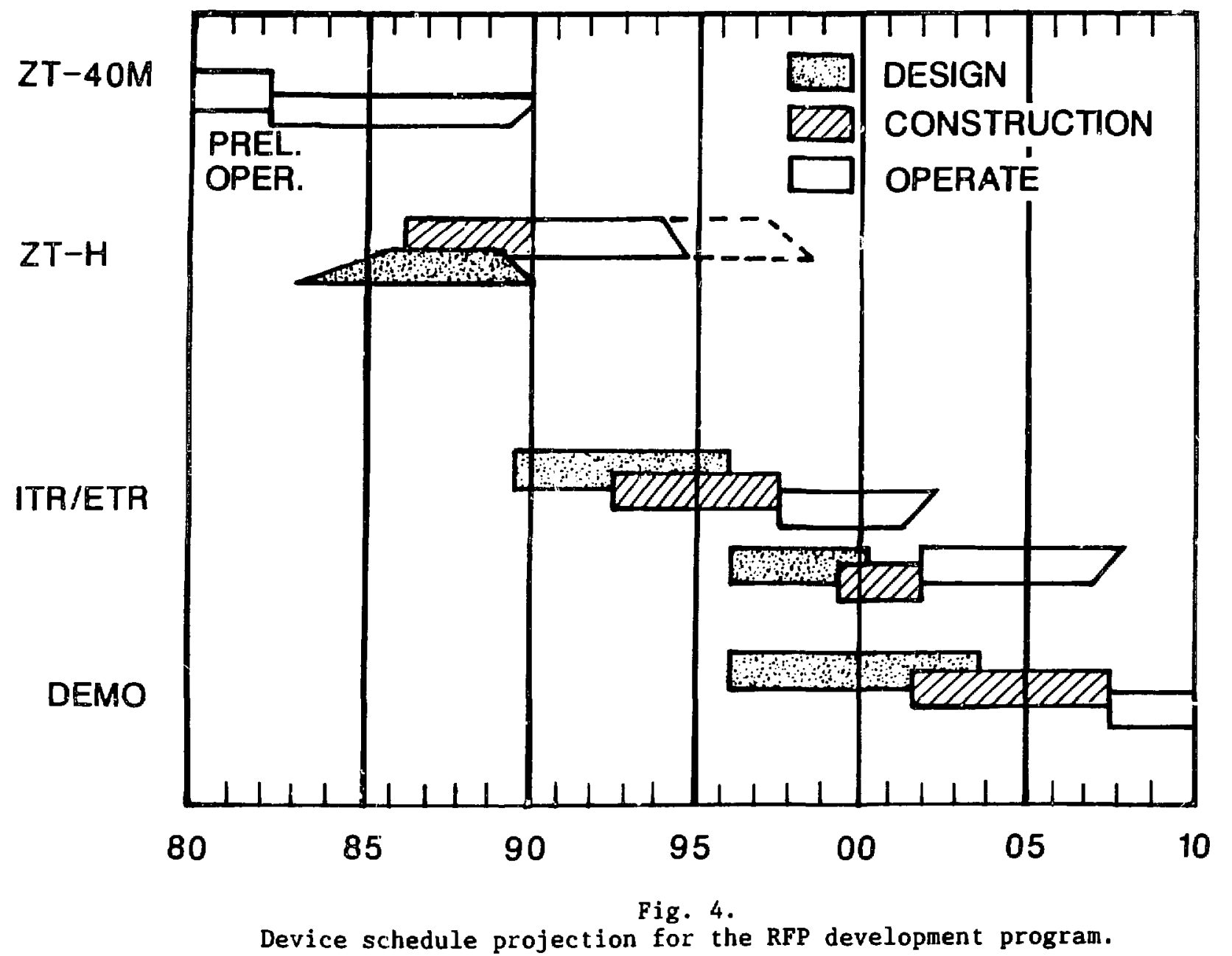




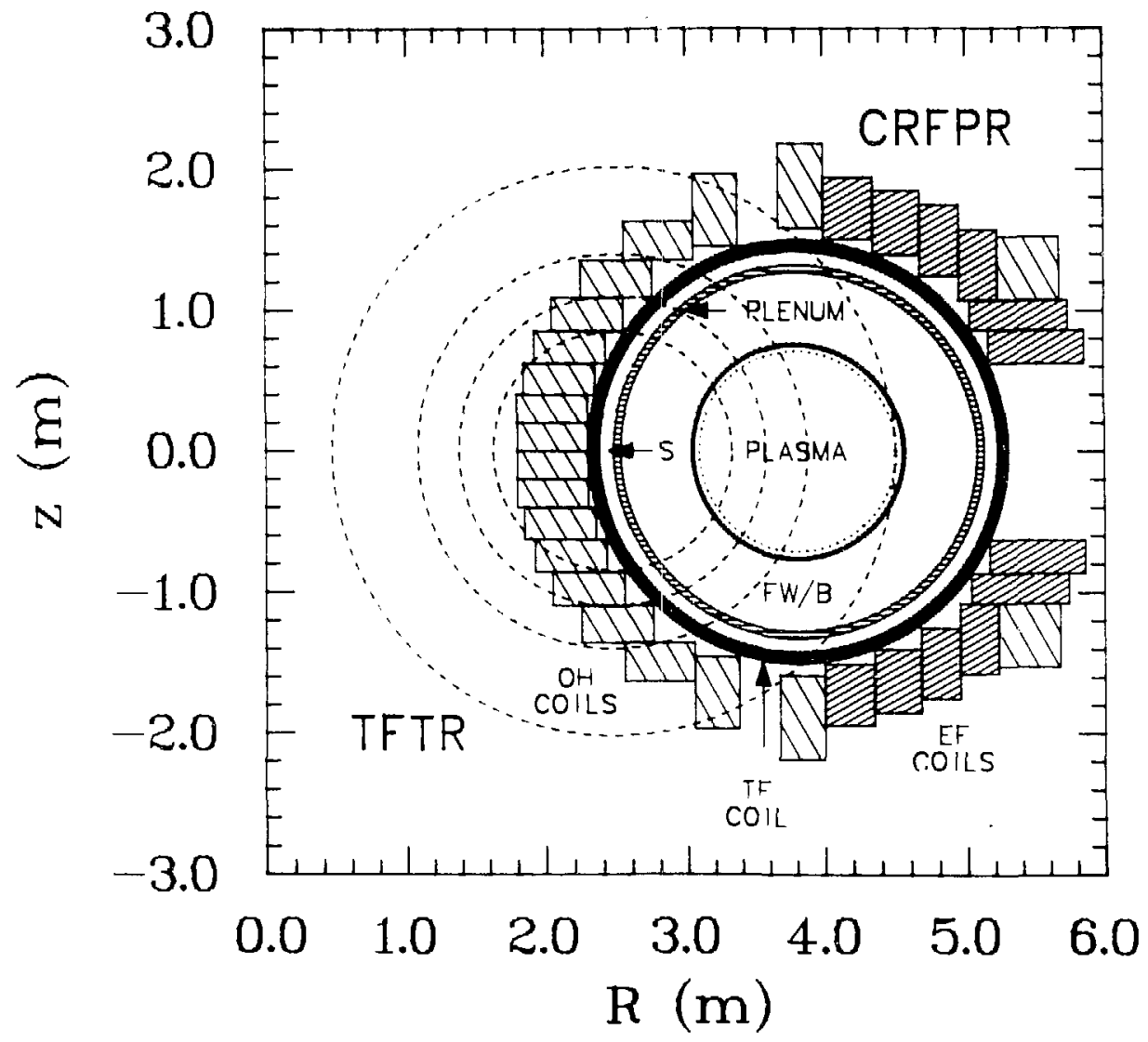

Fig. 5.

Scaled layout of the 1000-MWe (net) DT/CRFPR. 


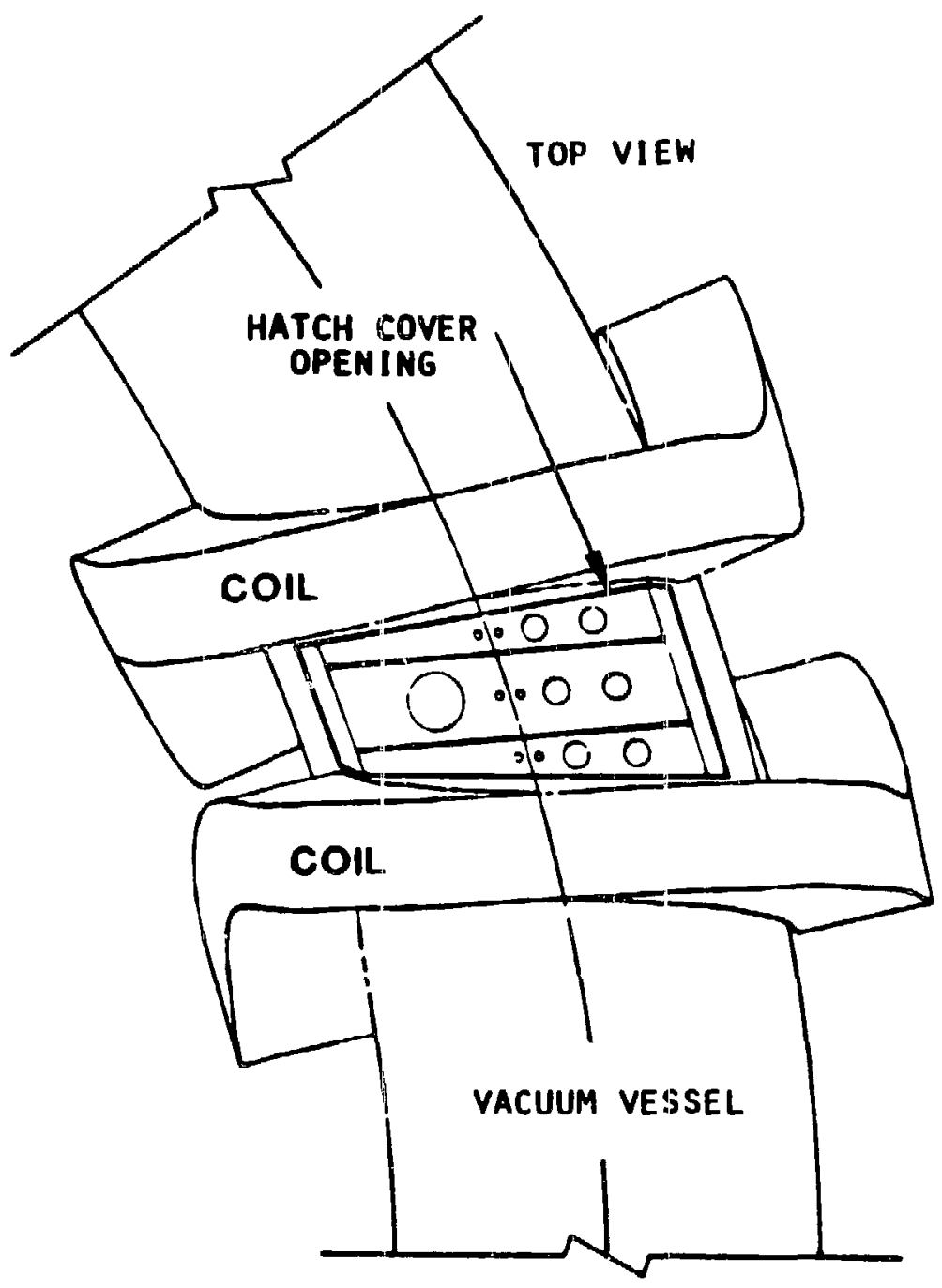

Fig. 6 .

MSR-IIB torus sector illustrating the $l=2$ modular coil set and a typical access port through the permanent vacuum boundary. 


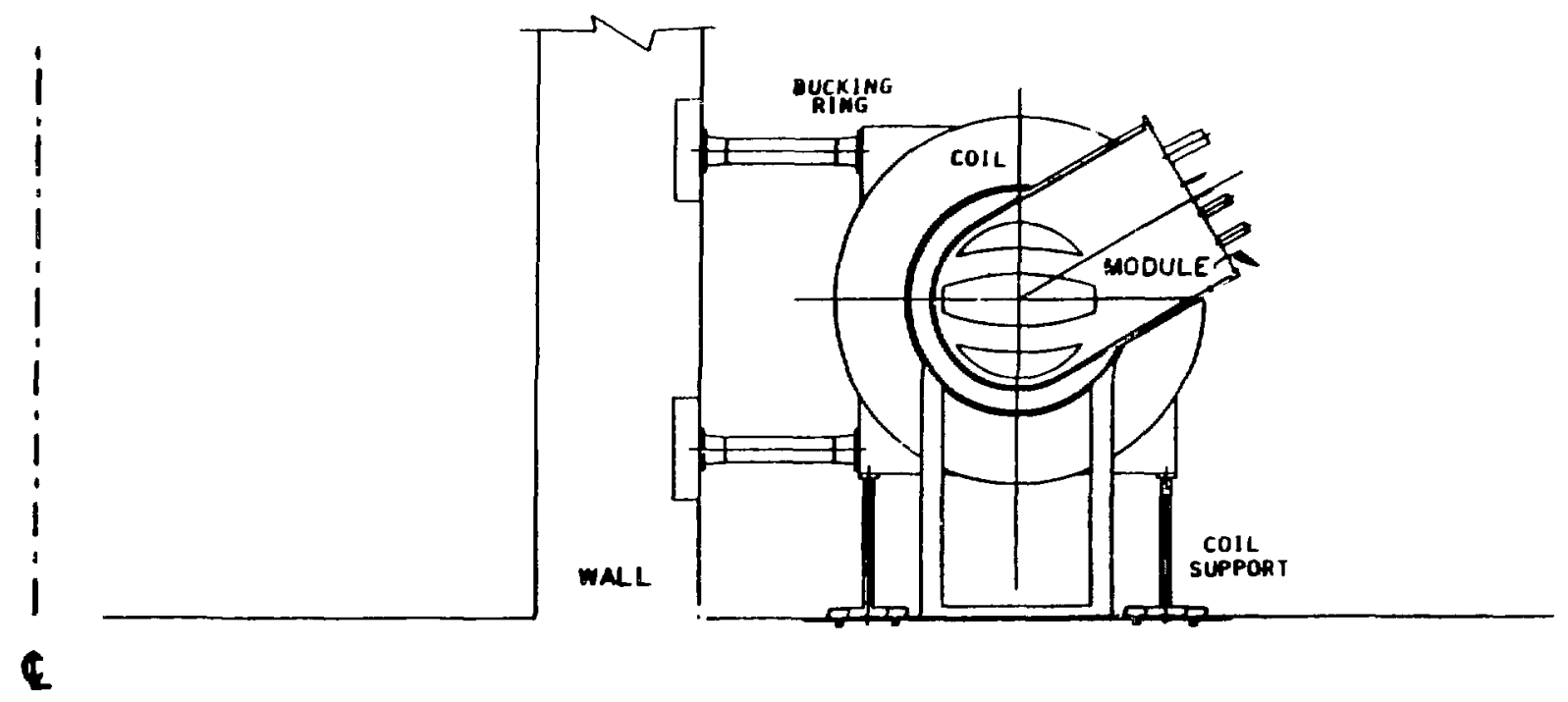

Fig. 7.

MSR-IIB reactor elevation view with a typical module orientation. 


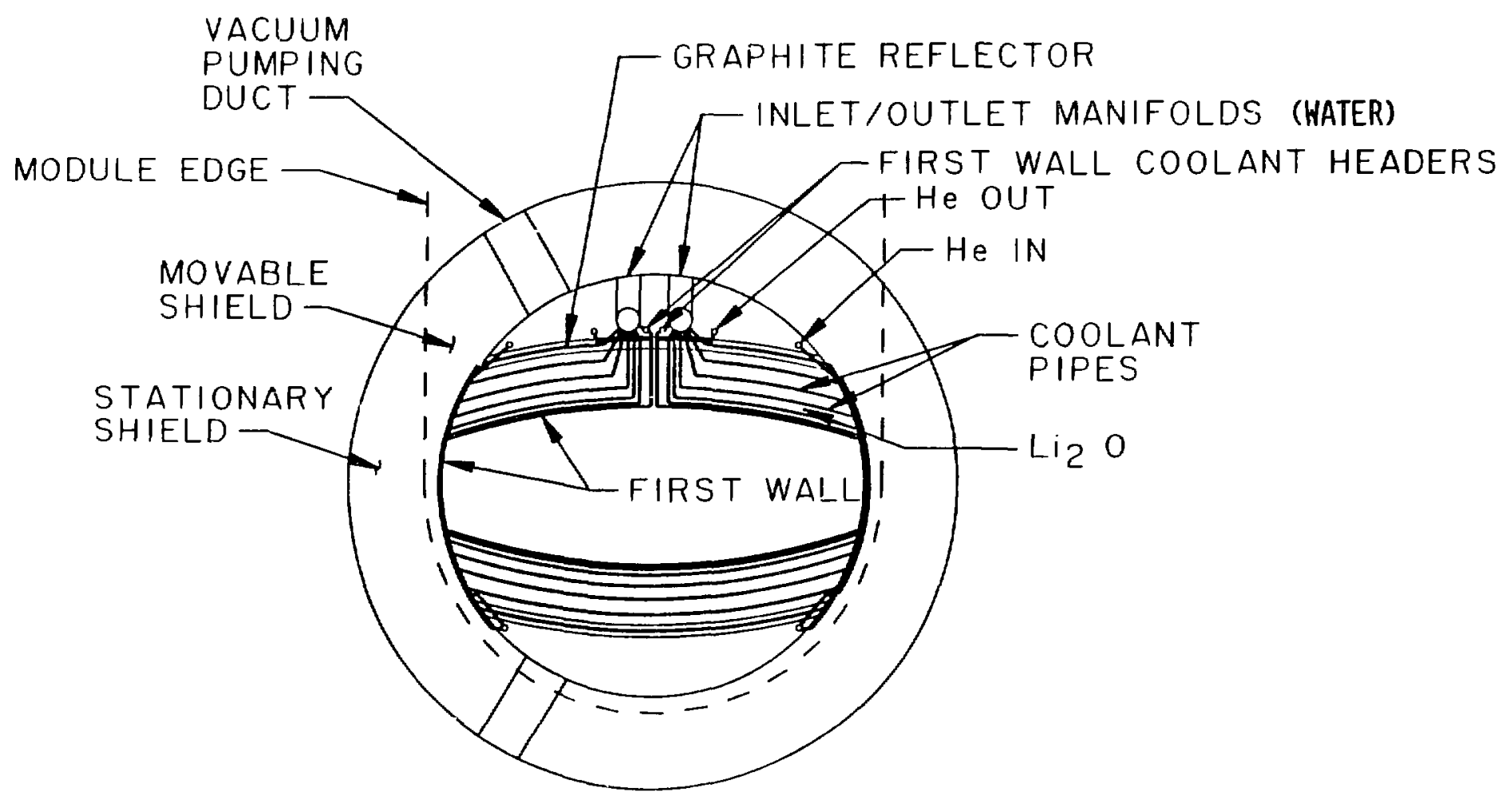

Fig. 8.

MSR-IIB first-wall/blanket/shield (FW/B/S) cross section. 


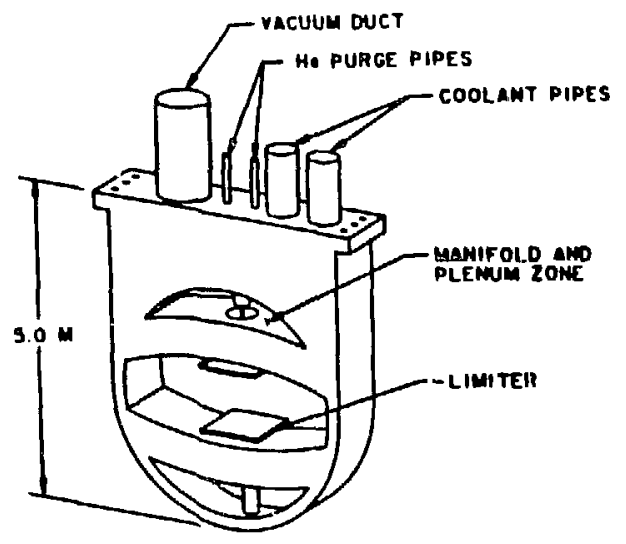

Fig. 9.

Typical MSR-IIB center module incorporating pumped limiter, first-wall, blanket, movable shield, vacuum flange, and duct access.

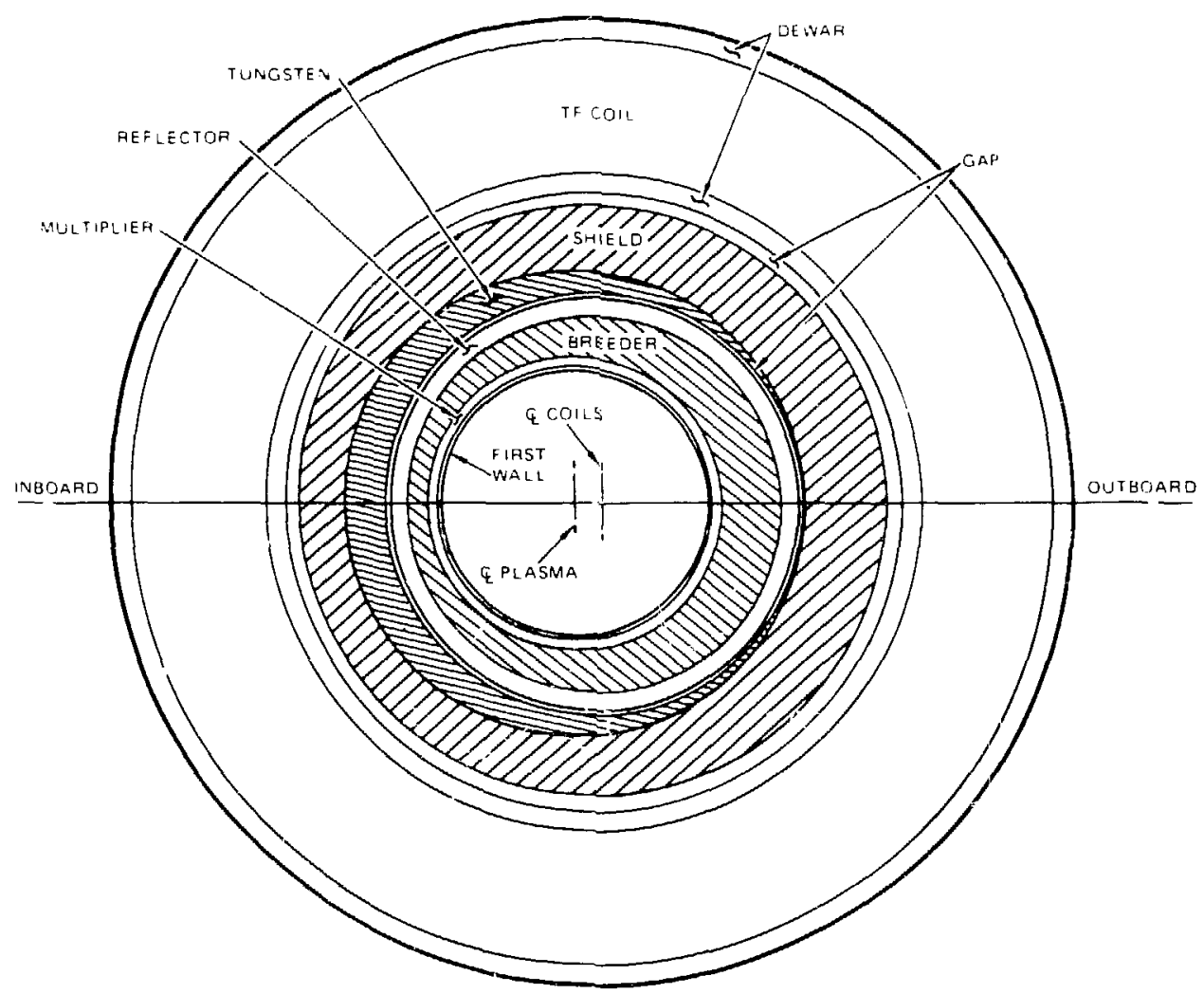

DESIGN APPROACH FOR BLANKET AND SHIELD

Fig. 10.

Design approach for EBTR blanket and shield showing coil-plane first-wall blanket/shield cross section. 

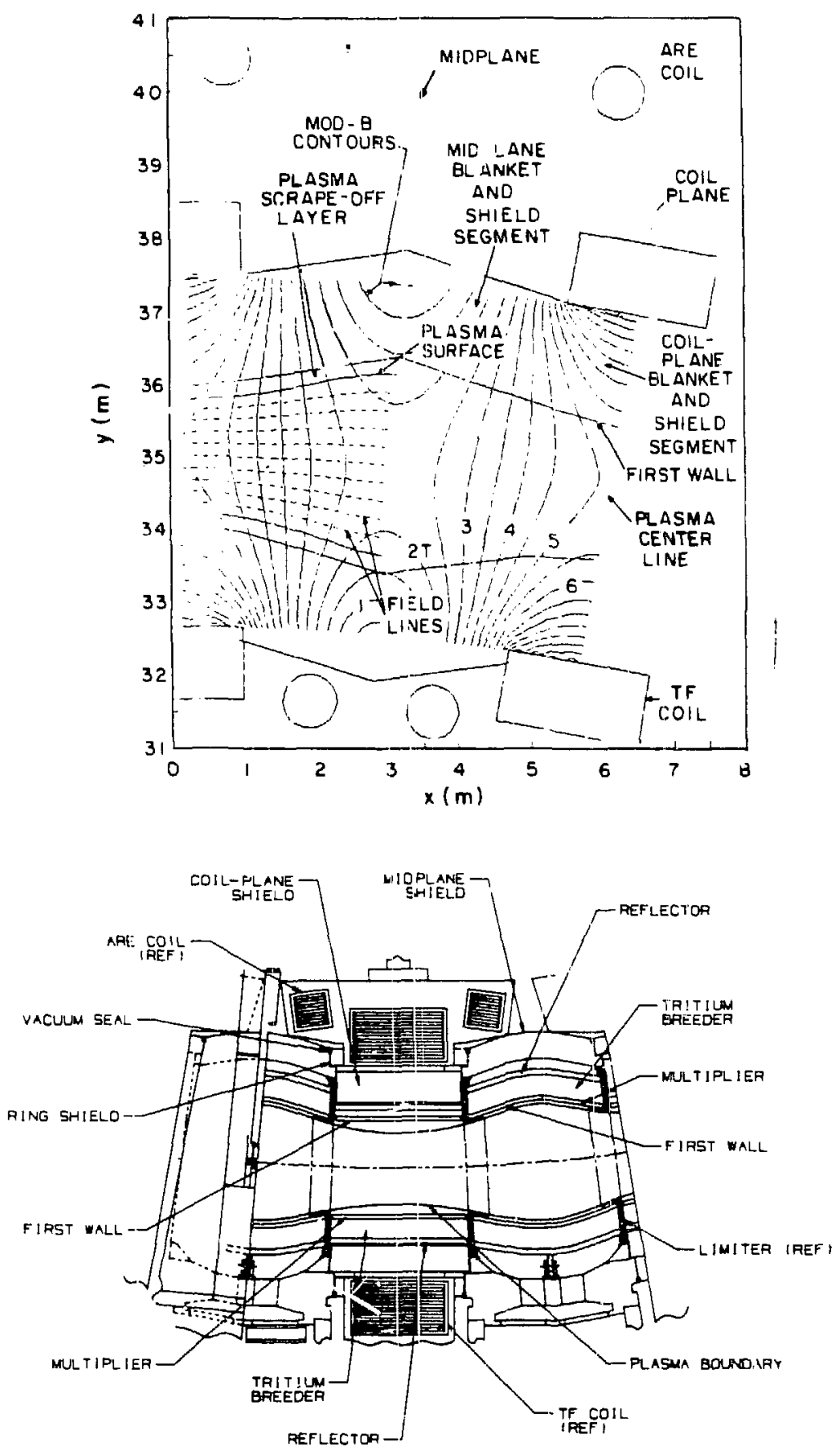

Plg. 11.

Cross section of first-wall/blankat/shield in the EBTR equatorial plane, showing the two-region blanket and the TP/ARE-coil locations. Top figure illustrates calculational model and bottom figure shows conceptual engineering design. Note that the vievs are diametrically opposite representations centerei on the midplane and coil plane, respectively. 


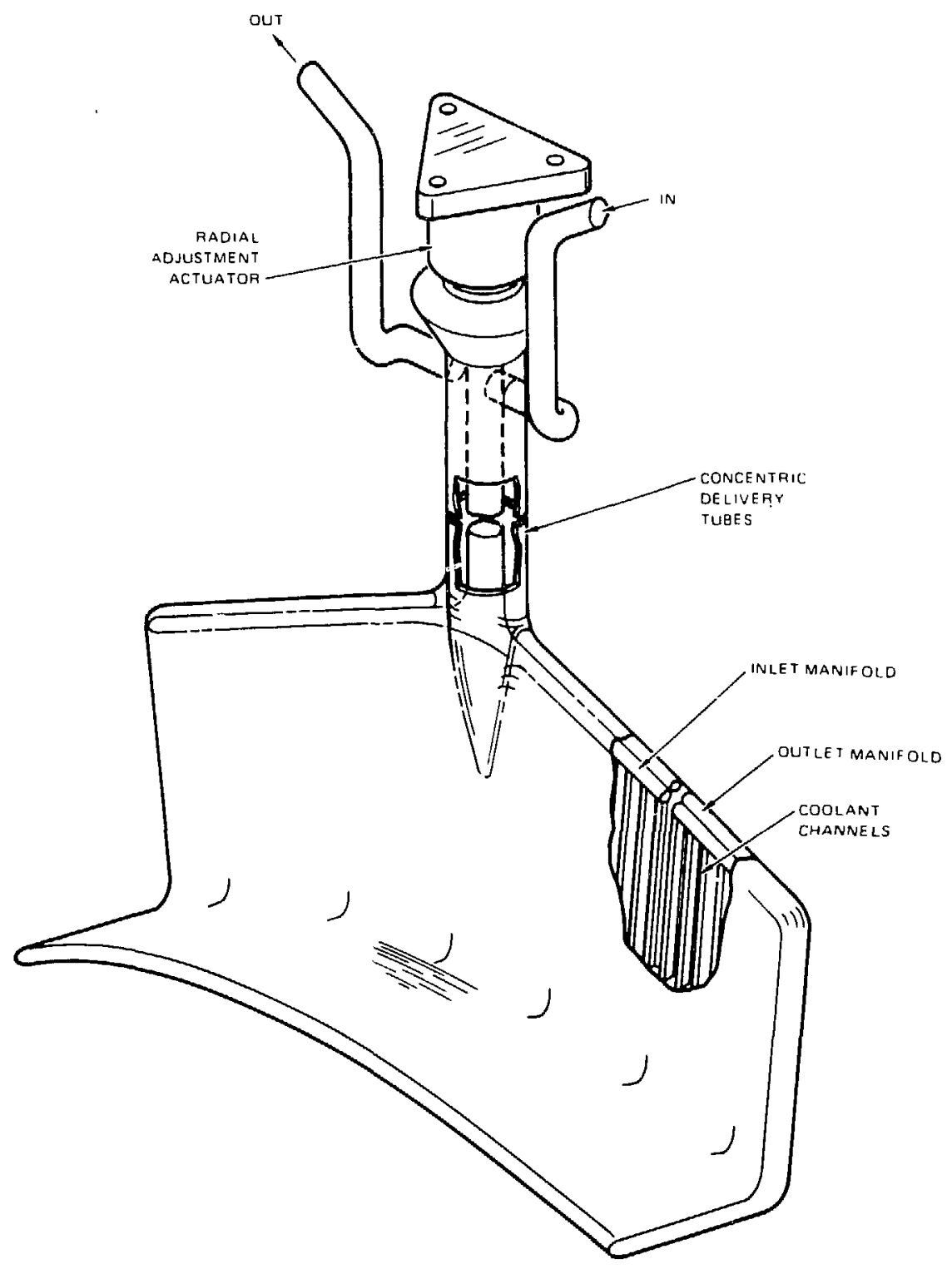

Fig. 12.

Isometric view of a typical limiter segment. 

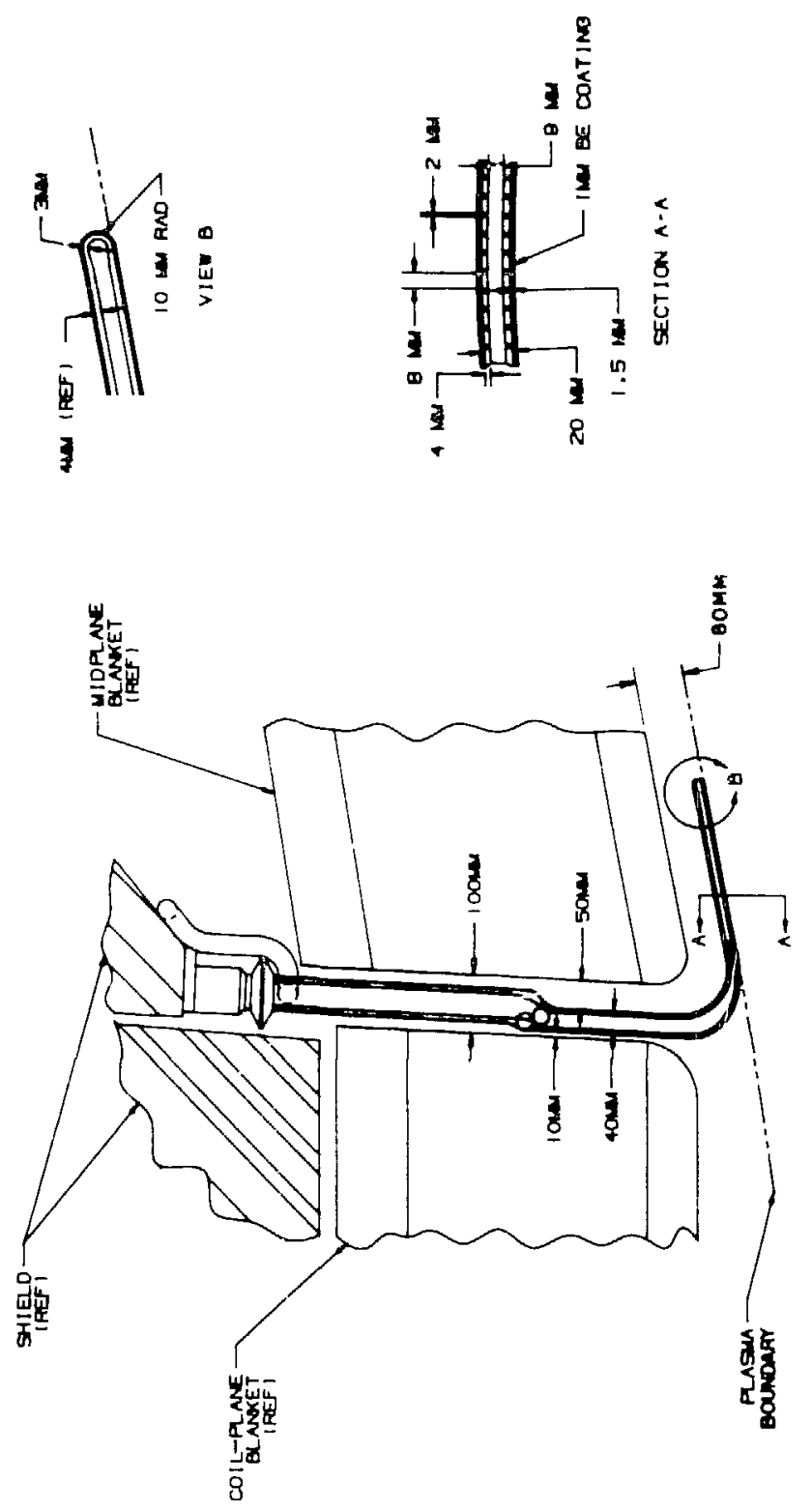

崩

$\stackrel{ \pm}{\square}$

車起

$\operatorname{sic}_{[\rightarrow 1}^{\infty}$

0
0
0
0
0
0
0
0
1
0
0
0
0
0 

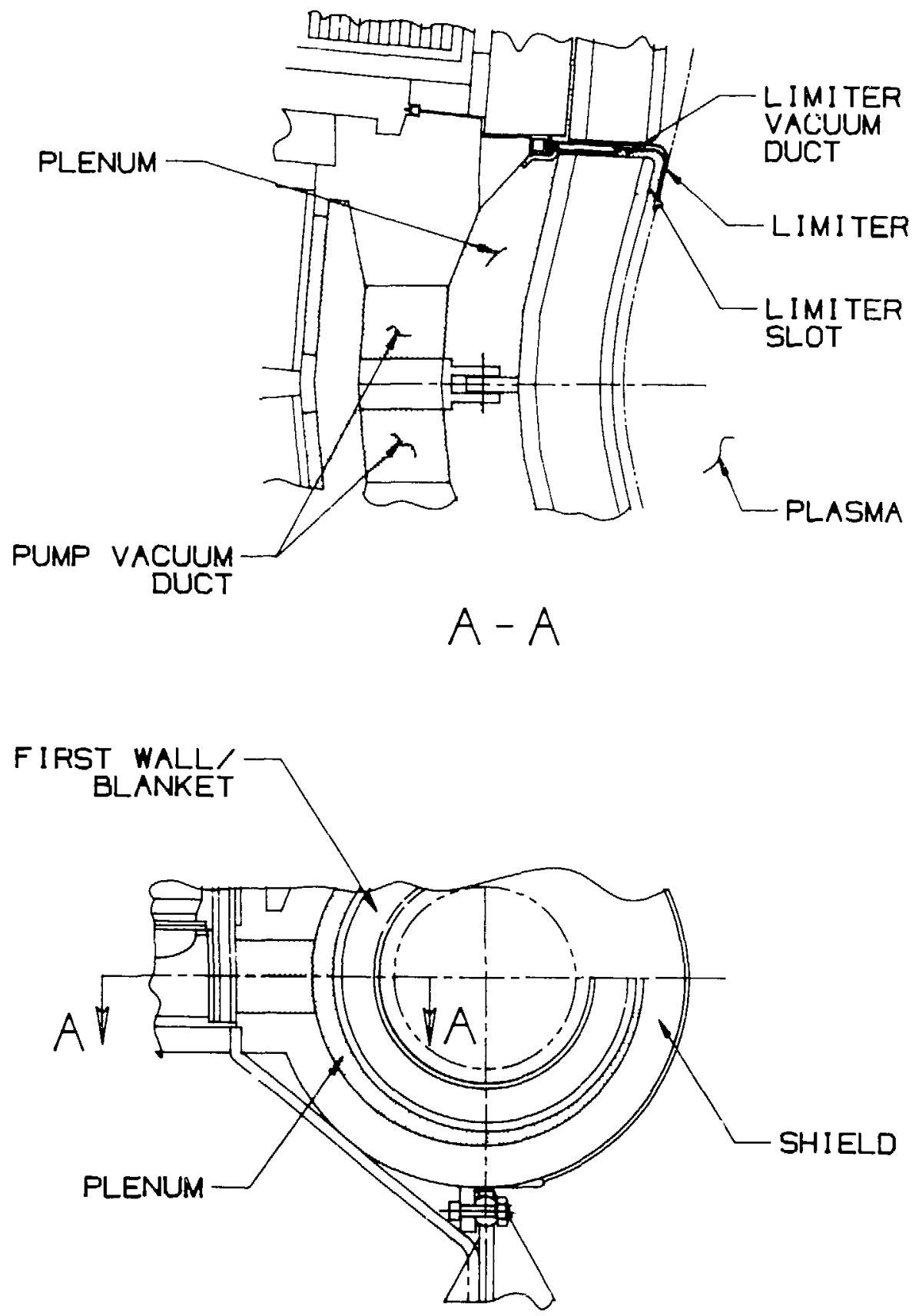

Fig. 14 .

0verall view of the limiter/vacuum system. The plenum region widens from $0.22 \mathrm{~m}$ at the inboard side to $0.52 \mathrm{~m}$ at the outboard side, where the plenum joins to vacuum ducting that leads to the (cryogenic) vacuum pumps. 